\title{
Hydrogeomorphic characteristics of streams in Bukit Timah Nature Reserve, Singapore
}

\author{
Y. Cai \\ National Biodiversity Centre, National Parks Board, \\ 1 Cluny Road, 259569 Singapore \\ cai_yixiong@nparks.gov.sg
}

\begin{abstract}
Field data and information from the literature on hydrology, hydraulic and geomorphic characteristics of the ten streams in Bukit Timah Nature Reserve were collected to form a baseline dataset with the aim of evaluating various functions that these streams perform, as well as the stresses and disturbances that they experience. Preliminary results show that majority of the channel reaches studied are functioning well, except that moderate to intense erosion was observed at the middle reaches of Lasia and Dairy Farm, and the lower reaches of Fern Valley and Wallace streams, where instability, undercutting and failure of banks have caused significant channelisation (bank widening and channel down-cutting). In general, the streams in Bukit Timah have little sediment, with low and small-sized bars visible only at the lower reaches of Fern Valley, Lasia and Wallace streams, which should not significantly affect the stream function if culverts and lined drains downstream are well maintained. However, several forced step-pools (artificial ponds) near the outlets of Taban, Seraya and Catchment streams and the middle of Jungle Fall stream continuously receive upstream sediments loads and accumulation of sediment with distinct siltation have obviously degraded the instream habitats. Follow-up actions on stream rehabilitation, adaptive management, future research and future monitoring are discussed.
\end{abstract}

Keywords. Geomorphology, headwaters, hill streams, hydraulics, hydrology, stream functions, tropical lowlands.

\section{Introduction}

Bukit Timah Nature Reserve (BTNR), Singapore, is an island within an island, "a mixture of lowland and coastal hill dipterocarp forest and secondary forest on the slope and summit of Singapore's highest hill, Bukit Timah" (Corlett, 1988). Rather than being a single conical hill, its peak at $163.6 \mathrm{~m}$ elevation is the highest point within "an assemblage of small hills and steep valleys, [that] constitutes the higher parts of Singapore island and also includes the least disturbed landforms and geomorphic processes" (Corlett, 1988). Similar hill clusters occur at Bukit Batok (peak approximately $107 \mathrm{~m}$ elevation; peak-to-peak distance $1300 \mathrm{~m}$ to the west of Bukit Timah) and Bukit Gombak (peak approximately $134 \mathrm{~m}$ elevation; peak-to-peak distance $3000 \mathrm{~m}$ to the northwest). Each of these hill clusters bears woody vegetation and gives rise to freshwater streams, but only BTNR retains primary forest. 


\section{Historical influences on stream systems}

A sharp boundary is evident between the steep hillsides of Bukit Timah and the surrounding gently sloping or level ground where development has occurred. Prior to development, the ten streams arising on Bukit Timah would have been the headwaters of a pristine natural drainage system joining and flowing a few kilometres to the sea. Since 1819, development of many kinds including agriculture, road and rail, residential and industrial constructions have removed forest from the level lowlands but left forest on the slopes (Corlett, 1992, 1997; Davison \& Chew, 2019). The stream headwaters each remain largely undisturbed for several hundred metres, with natural beds, banks and surrounding vegetation, but on reaching the base of the slopes their entire onward courses have been modified, mostly within straightened concrete channels. What were previously branches of single drainage systems have in some cases become isolated from one another (e.g., Dairy Farm stream and Wallace stream; Asas stream and Rail Corridor stream).

Although the construction of a track and then a road to and beyond Bukit Timah began in the 1820s (Lum \& Sharp, 1996; Davison \& Chew, 2019), disturbance of the downstream drainage at the western foot of Bukit Timah would have intensified when the road was given a hard surface. The construction of a railway line in 1925 would have further modified the lower reaches of Fern Valley, Rail Corridor and Asas streams. Currently the Rail Corridor, Dairy Farm and Lasia streams each show strong evidence of channel straightening in their middle or lower reaches. Based on the topographical map of 1924 (Fig. 1 A), the drainage surrounding the hill was still quite extensive then, the streams debouching from Bukit Timah representing the headwaters of several large rivers in Singapore, e.g. Kalang River, Pang Sua River and Rochor River.

The large granite quarries in the immediate vicinity of the hill had significant impacts on forest clearance, soil erosion, road construction, and presumably the lowering of the groundwater table upslope, as well as micro-climatic changes to the forest environment. In the case of Singapore Quarry, direct conversion of stream habitats that began at the lower reaches of one stream resulted in cutting off the several upstream branches, broke longitudinal connectivity, and left behind the fragmented and isolated upper stream branches (now Seraya and Jungle Fall streams). Though all quarry activities ceased operation in or before the 1990s, the impacts of these quarries on the streams of Bukit Timah (e.g. water quality, upslope erosion) can still be seen continuing. Ng (1994) commented that "Previously, the lower stretches of the streams of Jungle Fall Valley, just before it falls precipitously into the quarry, are on level ground with area covered with dense leaf-litter and is water-logged. Almost all of this area, because of the landslide, has been lost..."

The establishment of Dairy Farm by Singapore Cold Storage in 1929 at the north of the hill converted a large area of forest to farmland, which impacted the streams in the area quite significantly. Even now the hydrogeomorphic and physicochemical characteristics, and the biodiversity of the streams there are not comparable with other streams in the vicinity and are still in recovery. The farm 


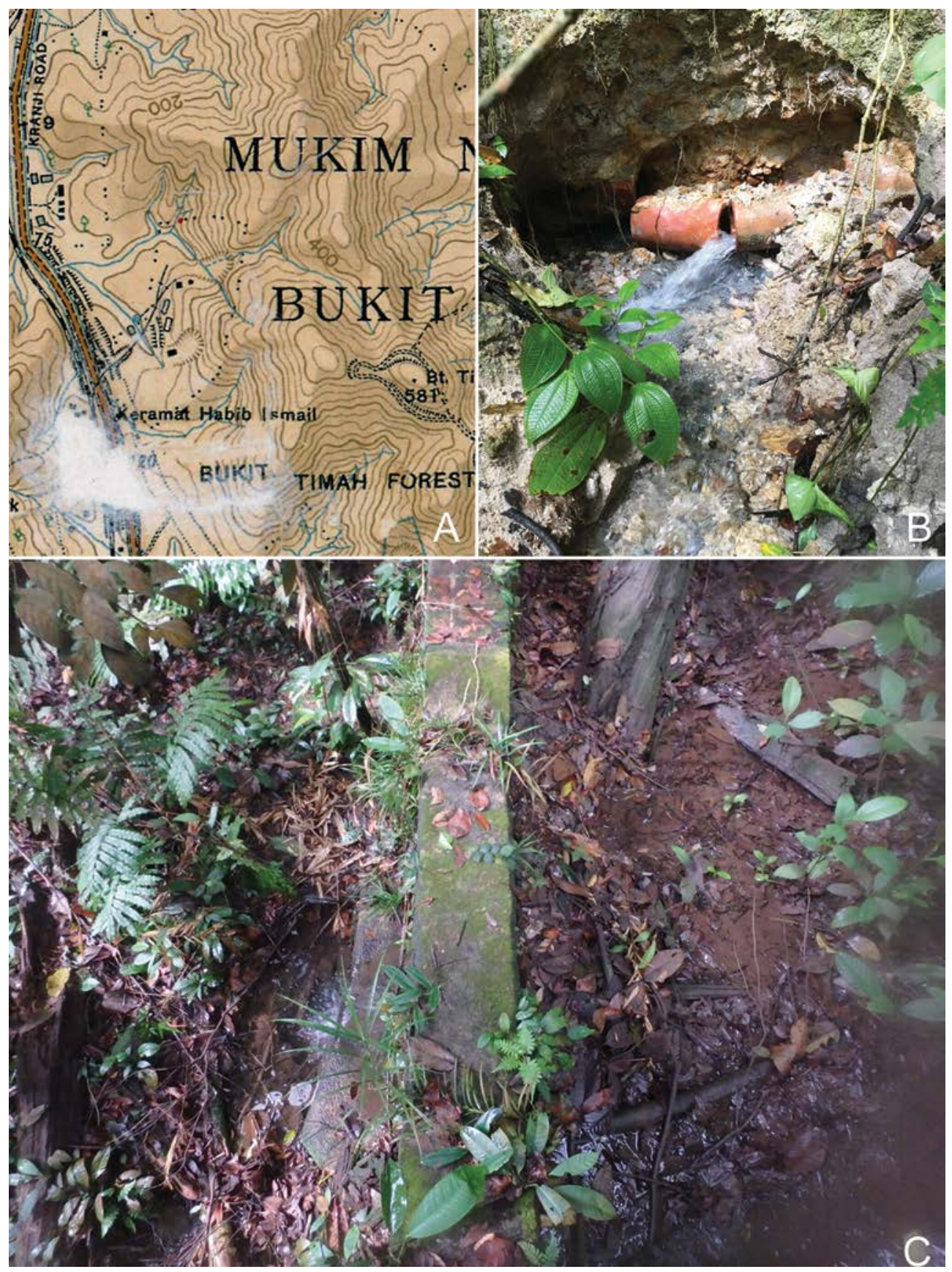

Fig. 1. A. Bukit Timah hill in 1924. B. Broken subsoil pipes causing channel headcutting at Wallace stream. C. "Pool" created by a low dam at Jungle Fall stream. (Photos: A, (C) National Library Board/Spatial Discovery; B \& C, Y. Cai) 
site comprised an area of 55 acres ( $22 \mathrm{ha}$ ) consisting of fertile ridges intersected by steep ravines, with granite outcrops here and there. It was chosen as a site for implementation of anti-malarial measures in the area due to the abundant water sources in the form of springs and seepages, and it would have been difficult to find a place more potentially malarious (Scharff, 1931). "Temporary oiling was employed until the permanent drainage was completed. The permanent drainage was erected by means of 5-inch subsoil pipes, laid at an average depth of $51 / 2$ feet. These pipes lead into an underground reservoir from which water is pumped into a service tank for farm use" (Scharff, 1931).

Stewart (1931) described the activities in detail. "The ravine is first cleared of trees and shrubs. Then three deep open drains, one central and two lateral (contour), are dug throughout the length of the ravine; these are left kutcha [i.e., left to settle] for 6 months or so (if necessary, oiling during this period is carried out). The effect of these drains is to lower the average level of the subsoil water throughout the ravine and to get rid once and for all of a large amount of accumulated water. If subsoiling were done straight off, this accumulation might never be got rid of at all and drainage be very unsatisfactory." One can imagine that the natural earth streams would have been modified significantly. The impact of subsoil pipes still remains, as occasionally discarded pipes are found to have been the culprits of channel headcutting when revealed by pouring water (Fig. 1 B). The brick dams at Jungle Fall valley (Fig. 1 C) are believed to have been built in the 1930s for anti-malarial purposes, so as to flush the lower stream regularly to clear out the mosquito larvae (Lum \& Sharp, 1996). The pool created by the dam had accumulated sediments to a depth of approximately $25 \mathrm{~cm}$ and sediment cores for a diatom and geochemical study were retrieved from this accumulation (Oon, 2012).

The Public Utilities Board pipeline bringing in fresh water from Johor to the Murnane Service Reservoir, constructed in the 1930s, was probably responsible for the blockage of Catchment stream and Lasia stream, and more recent residential development near to the BTNR Visitor Centre, has caused the conversion of the lower reaches of several streams to concrete lined drains. The lower reach of Catchment stream was further modified when the Bukit Timah Expressway (BKE) was built in the 1980 s.

The impact of various trails linking different parts of the reserve has been well documented by Chatterjea (1989a, b, 1994, 2007, 2012, 2019). The overland flow of water carrying sediment from the exposed ground of the trails will mostly end up in downslope streams. Some of the trails are also responsible for the blockage of stream courses (Chatterjea, 2019), leading to unnatural forced step-pool channel morphology (this study).

Recent developments in surrounding areas continue to pose threats to streams in BTNR. The upgrading of Dairy Farm Road, to link Upper Bukit Timah Road and the BKE, further impacted the streams in the Dairy Farm area, with a stream in the northwest of the area (Fu Yong stream) being fully concretised. The replacement of former Rifle Range, with the recently built Temasek Club has altered the connectivity of the lower reaches of Lasia stream. 
The streams of BTNR provide significant ecological functions that support a wide range of native fauna and flora through their in-stream habitats, riparian and stream valley vegetation. Most of these streams are experiencing ecological stresses caused by both natural and human induced disturbances to the terrestrial environment (Chatterjea, 2019). Although the aquatic biodiversity in streams has been comparatively well studied (Leong et al., 1996; Bastmeijer \& Kiew, 2001; Bickford et al., 2010; Lee, 2015; Lim et al., 2015; Cai et al., 2019; Li et al., 2019; Khoo et al., 2019), the hydrogeomorphic functions of the streams, their influence on stream water quality and biodiversity, as well as their impacts on the forest ecosystem have not been proportionally recognised. Mitigation and intervention measures required to address the stresses and disturbance are heavily reliant on our understanding of the hydrogeomorphic characteristics of the streams.

A study on the streams of BTNR was therefore initiated to update the information on stream geomorphology, to understand the hydrological processes, physicochemical characteristics, as well as the biodiversity and it ecological functions. The stresses and disturbances that all these streams are currently experiencing are identified and analysed, to address the problems at ecosystem level so that the biodiversity and the ecosystem services of the streams can be sustained in the long term. The area covered in this report includes BTNR and the surrounding nature areas, namely Dairy Farm Nature Park to the north, Hindhede Nature Park to the southwest, as well as Rifle Range Road to the south, the Rail Corridor to the west and the PUB pipeline to the east. The current publication mainly presents results on the hydrogeomorphic aspects of the stream study. The results on biodiversity and physicochemical characteristics of these streams are presented separately in this issue (Cai et al., 2019; Khoo et al., 2019; Li et al., 2019; Nguyen \& Cai, 2019).

\section{Methodology}

Stream mapping and qualitative observations were conducted from January 2015 to June 2018, while channel reaches were surveyed intensively from May to June 2018 to record several at-a-reach variables (Fig. 2-5). The period chosen was intended to minimise the effects of seasonal/temporal variability. The period from May to June is regarded as the intermonsoon just before the onset of the Southwest Monsoon period, with rainfall slightly lower than the monthly average. All sampling was conducted in fine weather conditions, except for a few additional samplings specifically taken to assess wet weather conditions which were not used to represent the points for comparison. Every channel reach was defined on the basis of a consistent alluvial or semi-alluvial morphology with longitudinal length defined as 10-20 multiples of the bank-full channel width (range 10-30 $\mathrm{m}$ in length).

\section{Hydrology}

Hydrology describes the transport of water from the watershed to the channel, including underground and surface water. Several parameters (e.g. precipitation/ 
runoff relationship; throughfall, stemflow and evapotranspiration; subsurface stormflow and surface runoff, etc.) are to be discussed, based on results from desktop information and literature review, with additional data from qualitative observations made in the past or through the current stream survey.

\section{Hydraulics}

Hydraulics refers to the transport of water in the channel, on any existing floodplain, and through sediments as comprehensively described by Harman et al. (2012). Both quantitative and qualitative data collected from the surveys were analysed based on simple hydrological principles and empirical formulae described in the numbered sections below. More complicated equations exist that give better estimates, but they require a more accurate understanding of channel characteristics and more accurate measurements. Comprehensive modelling work which may lead to a better understand of the stream hydrological characteristics is beyond the current study and may be pursued as future follow-up action. Flow dynamics, floodplain connectivity and groundwater/surface water exchange are then discussed. In the short duration of this study, it was not possible to observe storm discharge at each of the channels. Qualitative channel flow observations were made at each channel with respect to recent weather conditions and were used to infer general characteristics of catchment hydrology. For example, Fern Valley, Jungle Fall, Seraya, Dairy Farm and Wallace Streams were observed during or shortly after heavy rainfall to get a sense of how the streams appear during high discharge when under the impact of overland flow.

\subsection{Cross sections}

The cross-sectional area of a stream varies at every spot along the stream. The selection of each point for taking the measurement was stratified to be representative of the channel reach. Width of the stream was measured using a tape measure, followed by measuring its depth at 5 (width $<1 \mathrm{~m}$ ) or 7 (width $>1 \mathrm{~m}$ ) different points spaced evenly across the stream. The cross-sectional area of the stream was then calculated by estimating each sub-area to be either triangular or trapezoidal. The cross-section in bank-full conditions was only observed and recorded for selected reaches where a risk in stream hydraulic functioning was thought to exist. The area was then calculated based on bank-full depth and width measured in the field. Some of the bank-full indicators commonly used in temperate regions (e.g. top of the bank, discontinuity in vegetation, slope break, scour line, top of the point bar) (Galia \& Hradecký, 2014a; Adam \& Spotila, 2005) do not seem to be easy to apply in tropical conditions like Singapore, due possibly to the frequent rainfall events and the form of the bankside forest vegetation. Thus, when there was more than one environmental marker to suggest the bank-full level, a conservative approach (i.e., to ensure that the maximum cross-sectional area was captured) was applied by using the higher of the markers. 


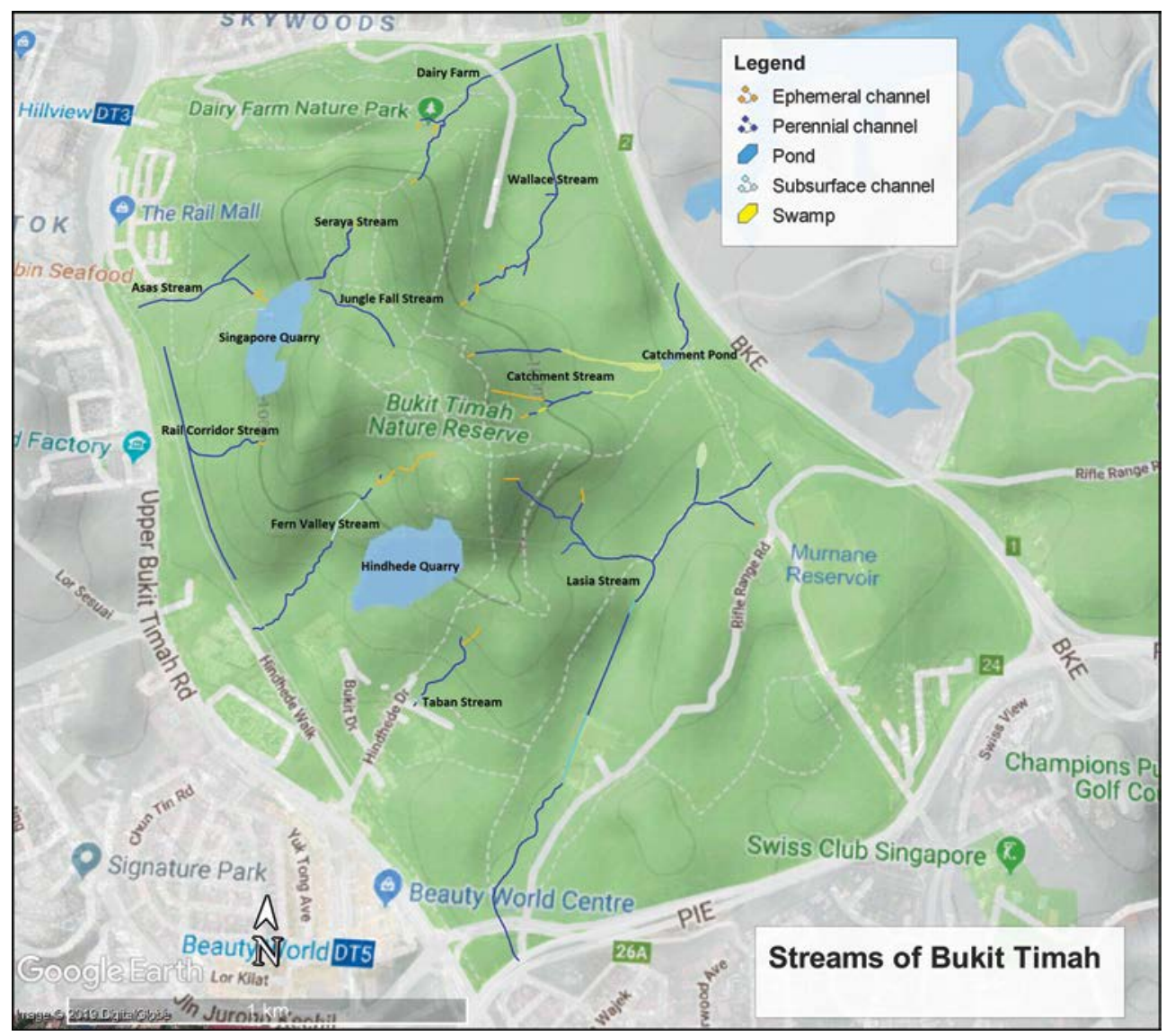

Fig. 2. Streams in Bukit Timah Nature Reserve (Source: basemap Google Earth@2019).

\subsection{Hydraulic radius}

Factors determining the overall flow velocity in a stream are expressed by the hydraulic radius $(\mathrm{R})$. Put simply, $\mathrm{R}$ is the cross-sectional area (A), divided by the wetted perimeter $(\mathrm{P})$.

$$
\mathrm{R}=\mathrm{A} / \mathrm{P}
$$

Where $\mathrm{R}=$ hydraulic radius $(\mathrm{m})$

$A=$ cross sectional area $\left(\mathrm{m}^{2}\right)$

$\mathrm{P}=$ wetted perimeter $(\mathrm{m})$

\subsection{Velocity}

Dry weather velocity measures the speed at which the water is flowing in the stream. The flow rate of the stream water was measured using a HACH FH950.1 Velocity Flow Meter, with three replicates of readings taken at each site. Predicting flow 


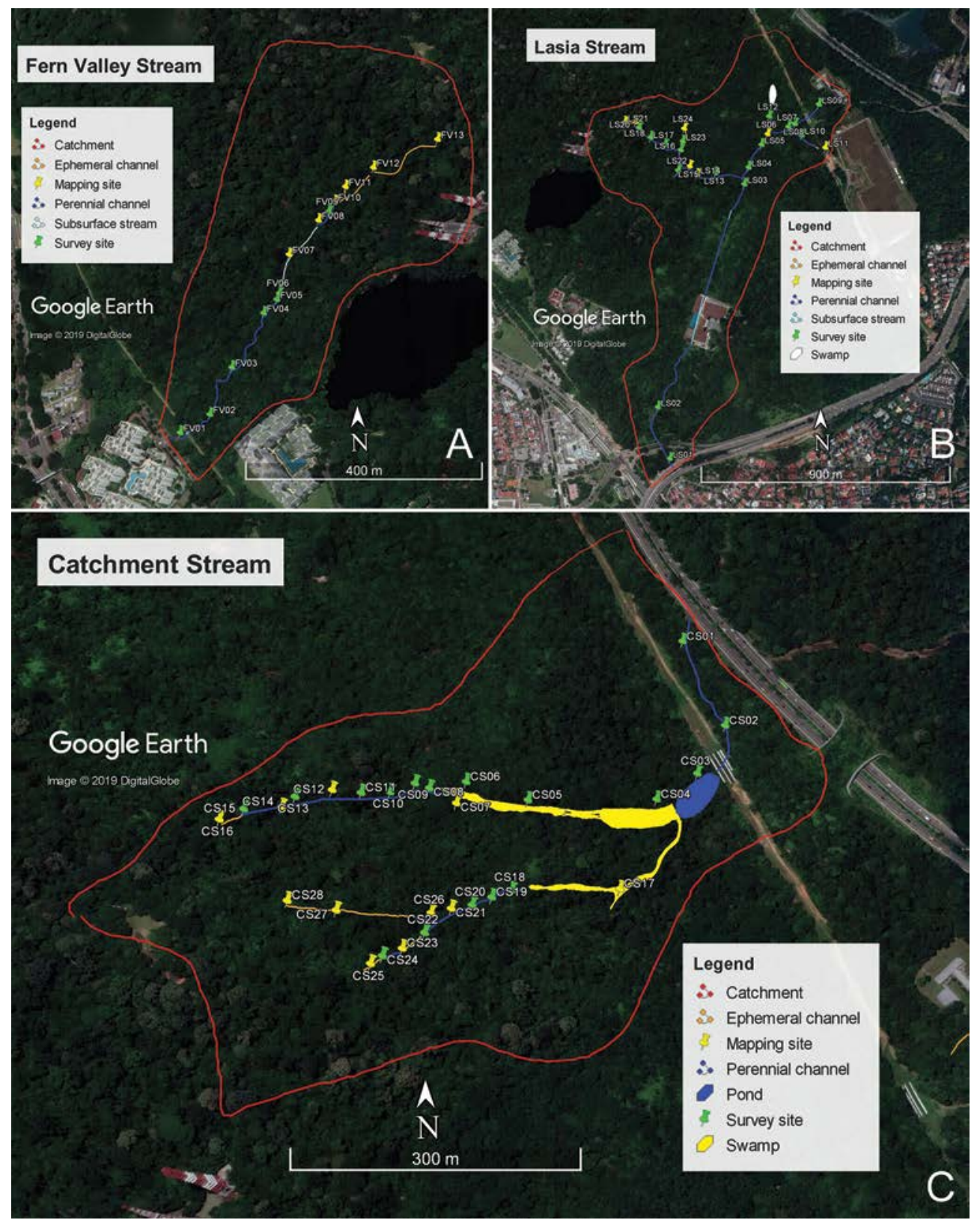

Fig. 3. A. Fern Valley stream (FV). B. Lasia stream (LS). C. Catchment stream (CS) (Source: base map Google Earth@2019).

velocity is determined by slope $(\mathrm{S})$ in relation to the depth and cross-sectional shape, combined as hydraulic radius (R), and channel roughness, Manning's ' $n$ ' (n). The relationship of these parameters is expressed mathematically as: 


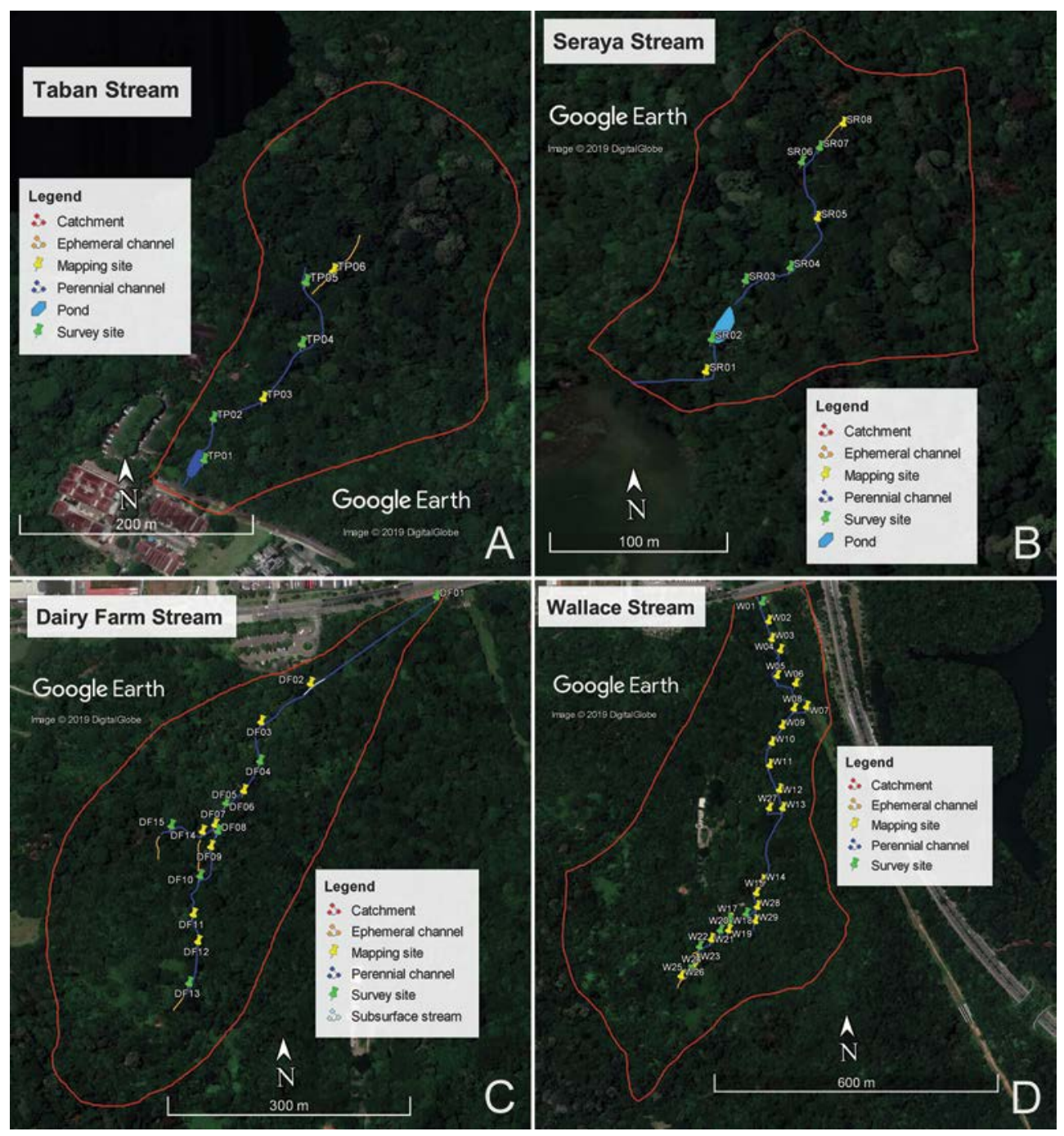

Fig. 4. A. Taban stream (TB). B. Seraya stream (SR). C. Dairy Farm stream (DF). D. Wallacestream (WL) (Source: base map Google Earth@2019)

$$
\mathrm{V}=\left(\mathrm{R}^{2 / 3} \mathrm{~S}^{1 / 2}\right) / \mathrm{n}
$$

Where: $\mathrm{v}=$ velocity of flow $(\mathrm{m} / \mathrm{s})$

$\mathrm{R}=$ hydraulic radius of flow $(\mathrm{m})$

$\mathrm{S}=$ channel slope (expressed as a ratio of vertical distance dropped against horizontal distance, e.g. 0.001)

$\mathrm{n}=$ Manning's $\mathrm{n}$ (a unitless value)

\subsection{Discharge rate}

The dry weather discharge rate (basal flow discharge) will determine the volume of water flowing through a particular cross-sectional area of the stream. It is estimated 

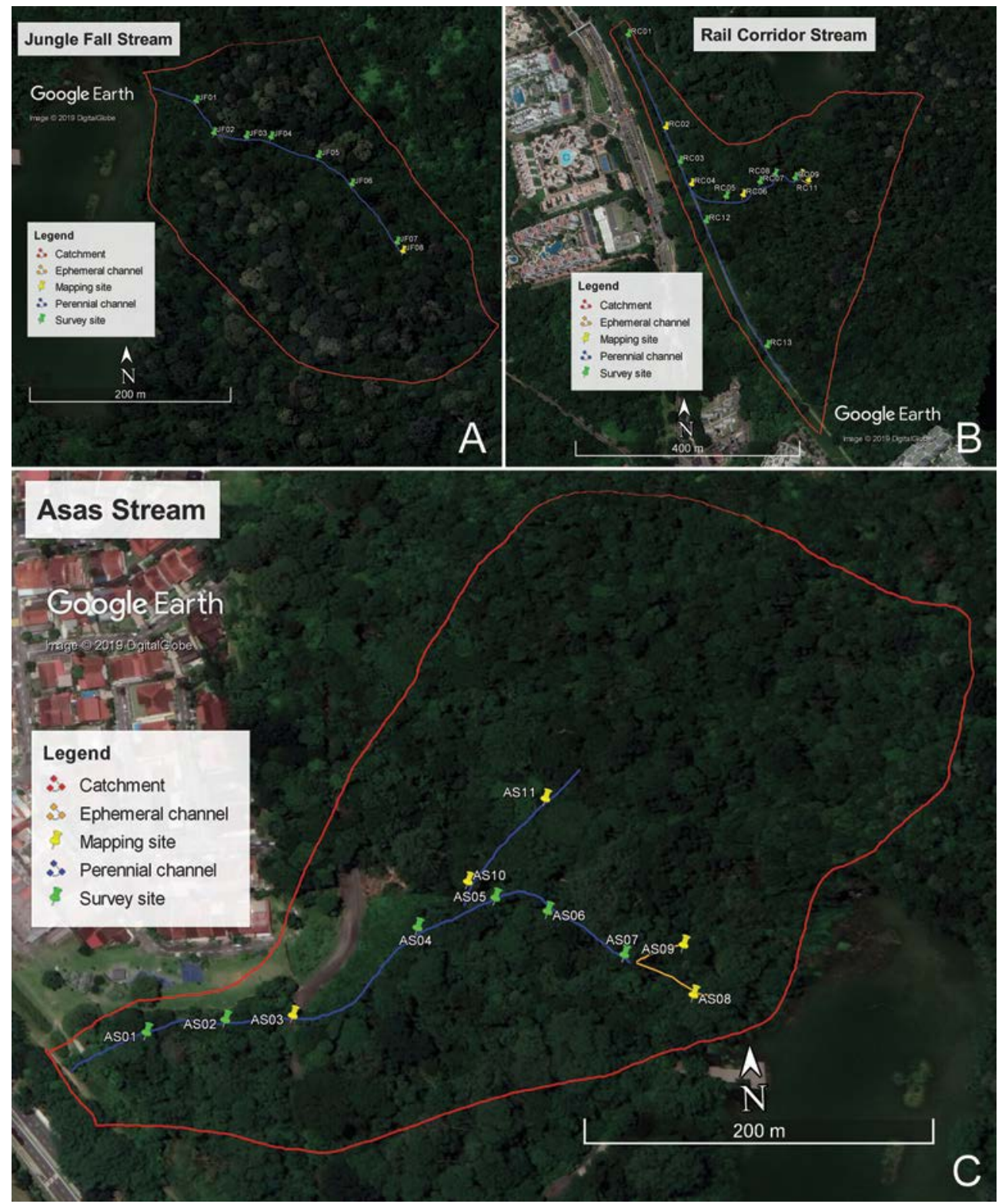

Fig. 5. A. Jungle fall stream (LS). B. Rail Corridor stream (RC). C. Asas stream (AS). (Source: base map Google Earth@2019).

from a calculation of two other parameters: dry weather velocity and the cross-sectional area of the stream. The measured cross-sectional area (A) of the channel at the existing flow level is multiplied by the measured velocity (v) to obtain the existing discharge $(\mathrm{Q})$. 


$$
\mathrm{Q}=\mathrm{Av}
$$

Where: $\mathrm{Q}=$ discharge $\left(\mathrm{m}^{3} / \mathrm{s}\right)$

$\mathrm{A}=$ area of cross section $\left(\mathrm{m}^{2}\right)$

$\mathrm{v}=$ velocity $(\mathrm{m} / \mathrm{s})$

\subsection{Bank height ratio}

The bank height ratio (BHR) is a direct measure of channel incision. This ratio is calculated as follows:

$$
\mathrm{BHR}=\mathrm{Dtob} / \mathrm{Dbf}
$$

Where Dtob $=$ the depth from the top of the lowest bank to the thalweg

$\mathrm{Dbf}=$ the depth from the bank-full elevation to the thalweg.

The thalweg is defined as a line connecting the lowest points between successive cross-sectional profiles, hence it is effectively a contour line illustrating the deepest part of the channel along the stream.

A BHR of 1.0 defines the point at which all flows greater than bank-full must then spread onto a floodplain(C and E of Rosgen's stream types) or bank-full bench/ floodprone area (A and B of Rosgen's stream types).

\subsection{Entrenchment Ratio}

The entrenchment ratio (ER) is a measure of the width of the flood-prone area in relation to the bank-full width (Rosgen, 1994). The width of the flood-prone area is measured at a stage of double the bank-full maximum depth. Therefore, it is possible to have a stream that is incised, e.g., BHR of 1.8, but not entrenched if the floodplain is wide. The ER is calculated in a riffle cross section as follows:

$$
\mathrm{ER}=\mathrm{FW} / \mathrm{BW}
$$

Where $\mathrm{FW}=$ flood-prone width, measured at a stage of twice the bank-full maximum depth

$$
\mathrm{BW}=\text { bank-full riffle width }
$$

The BHR and ER work well together (Table 1) to quantify floodplain connectivity (Harman et al., 2012). For all stream types, a BHR of 1.0 indicates that the stream is not incised and has access to a floodplain or floodprone area. However, the ER will naturally vary by stream type. Streams in v-shaped valleys (A stream types) and colluvial valleys (B stream types) will have lower entrenchment ratios than streams in alluvial valleys (C, E and DA stream types).

\subsection{Manning's $n$ value}

Manning's n or Manning's Friction Factor indicates the roughness and the frictional resistance of a given channel. It is essential in evaluating the flow through an earth 
Table 1. Floodplain Connectivity Performance Standards (Harman et al., 2012)

\begin{tabular}{llll}
\hline Measure Method & Functioning & Functioning at-risk & Not functioning \\
\hline Bank Height Ratio (BHR) & 1.0 to 1.2 & 1.3 to 1.5 & $>1.5$ \\
& & & \\
$\begin{array}{l}\text { Entrenchment Ratio (ER) } \\
\text { for C and E Stream Types }\end{array}$ & $>2.2$ & 2.0 to 2.2 & $<2.0$ \\
$\begin{array}{l}\text { Entrenchment Ratio (ER) } \\
\text { for B and Bc Stream Types }\end{array}$ & $>1.4$ & 1.2 to 1.4 & $<1.2$ \\
\hline
\end{tabular}

or rocky channel. There are two most important factors that affect the estimation of Manning's n, namely, the shape of the earth channel, and the type and size of materials that can be found in the earth channel. Using Cowan's (1956) method (Table 2), the Manning's $n$ value for that particular point can be estimated.

$$
\mathrm{N}=\left(\mathrm{n}_{0}+\mathrm{n}_{1}+\mathrm{n}_{2}+\mathrm{n}_{3}+\mathrm{n}_{4}\right) \mathrm{M}_{5}
$$

\subsection{Stream Power}

Stream power is the ability of the stream to do work, where work is defined as the conversion of potential energy (elevation change) to kinetic energy. Most of the kinetic energy is dissipated through friction from the bed and banks. However, a small portion is available to accomplish geomorphic work such as the entrainment and transport of sediment (Bagnold, 1960). Bagnold (1977) and Phillips (1989) provide a crosssectional stream power calculation, which is a physically based measure of sediment transport capacity. Thus, cross-sectional stream power can be written as:

$$
\Omega=\gamma \mathrm{QS}
$$

Where $\Omega=$ stream power per unit length $(\mathrm{W} / \mathrm{m})$

$\gamma=$ specific weight of water $\left(9810 \mathrm{~N} / \mathrm{m}^{3}\right)$ (cf. Knighton, 1999)

$\mathrm{Q}=\operatorname{discharge}\left(\mathrm{m}^{3} / \mathrm{s}\right)$

$\mathrm{S}=$ slope $(\mathrm{m} / \mathrm{m})$.

Mean stream power is related to competence (Lecce, 1997) and can be expressed as:

$$
\omega=\gamma \mathrm{RSV}=\Omega / \mathrm{W}=\tau \mathrm{V}
$$

Where $\omega=$ unit or mean stream power $\left(\mathrm{W} / \mathrm{m}^{2}\right)$

$\mathrm{R}=$ hydraulic radius $(\mathrm{m})$

$\mathrm{V}=$ velocity $(\mathrm{m} / \mathrm{s})$

$\mathrm{W}=$ width $(\mathrm{m})$. 
Table 2. Component values for Cowan's method of estimating Manning's n value.

\begin{tabular}{|c|c|c|c|}
\hline Basic n value & $\mathbf{n}_{0}$ & $\begin{array}{l}\text { Effect of obstructions (debris } \\
\text { deposits, roots, boulders) }\end{array}$ & $\mathbf{n}_{3}$ \\
\hline Earth & 0.020 & $\begin{array}{l}\text { Negligible (few scattered } \\
\text { obstructions) }\end{array}$ & 0 \\
\hline Rock cut & 0.025 & $\begin{array}{l}\text { Minor (obstructions isolated, } 15 \% \\
\text { of area) }\end{array}$ & 0.050 \\
\hline Fine Gravel & 0.024 & $\begin{array}{l}\text { Appreciable (interaction between } \\
\text { obstacles which cover } 15-50 \% \text { of } \\
\text { area) }\end{array}$ & $0.020-0.030$ \\
\hline Coarse gravel & 0.028 & $\begin{array}{l}\text { Severe (obstruction cover } \\
>50 \% \text {, or caused turbulence over } \\
\text { most of area }\end{array}$ & $0.040-0.060$ \\
\hline Cobble & $0.030-0.050$ & & \\
\hline Boulder & $0.040-0.070$ & & \\
\hline Surface irregularity & $\mathbf{n}_{1}$ & Vegetation & $\mathbf{n}_{4}$ \\
\hline Smooth & 0 & None or no effect & 0 \\
\hline $\begin{array}{l}\text { Minor (slight eroded or } \\
\text { scoured) }\end{array}$ & 0.005 & $\begin{array}{l}\text { Supple seedlings or dense } \\
\text { grass/weeds }\end{array}$ & $0.005-0.010$ \\
\hline Moderate (moderate slumping) & 0.010 & $\begin{array}{l}\text { Bushy growths, no growth on } \\
\text { streambed; grass height of flow }\end{array}$ & $0.010-0.025$ \\
\hline \multirow[t]{2}{*}{$\begin{array}{l}\text { Severe (badly slumped, eroded } \\
\text { banks or jagged rock surfaces) }\end{array}$} & 0.020 & $\begin{array}{l}\text { Young tree intergrown with weeds; } \\
\text { grass twice depth of flow }\end{array}$ & $0.025-0.050$ \\
\hline & & $\begin{array}{l}\text { Bushy growth on banks, dense } \\
\text { growth in stream; tree intergrown } \\
\text { with weeds; full foliage }\end{array}$ & $0.05-0.10$ \\
\hline $\begin{array}{l}\text { Variation in cross-section } \\
\text { shape causing turbulence }\end{array}$ & $\mathbf{n}_{2}$ & Meandering (multiply) & $\mathbf{m}_{5}$ \\
\hline Change occurs gradually & 0 & Minor (sinuosity 1.0-1.2) & 1.00 \\
\hline $\begin{array}{l}\text { Occasional changes from large } \\
\text { to small or side-to-side shifting } \\
\text { of flow }\end{array}$ & 0.005 & Appreciable (sinuosity 1.2-1.5) & 1.15 \\
\hline Frequent changes & $0.010-0.015$ & Severe (sinuosity $>1.5$ ) & 1.3 \\
\hline
\end{tabular}




\section{Geomorphology}

Geomorphology deals with the transport of wood and sediment to create diverse bed forms and dynamic equilibrium. The fieldwork was conducted following methods that have been established in other regions.

\subsection{Longitudinal profile, catchment area, channel gradients}

Distance and elevation were surveyed for each channel reach from the stream outlet to its initiation point at the channel head. Actual ground distance was measured in the field by using a measuring tape for most of the points but was converted to horizontal distance for the final plotting of longitudinal profiles. Some of the distances which were difficult to measure in the field (e.g., steep slopes), as well as calculation of channel and slope gradients, were estimated based on the GPS point reading obtained from the field overlain into Google Earth maps. Longitudinal profile of streams was generated based on the main (stem) stream channel which started at stream outlet to its channel at highest elevation. Catchment areas and mean slope/channel gradients upstream of individual channel-reach were calculated and estimated based on overlaying contoured map with Google Earth (Google Earth@2019) and the results were compared to obtain a reasonable estimation.

\subsection{Channel head and channel morphology}

Channel substrate was surveyed qualitatively along the length of the channel until a channel head was reached. This was done simultaneously with the longitudinal profile survey. A channel head can be a relatively diffuse feature, the identification of which is subjective, or a very discrete and prominent break in the surface associated with a headcut (Wohl, 2018). The channel reach morphology was classified based on Montgomery \& Buffington (1997) and Galia \& Hradecký (2014a). Rosgen's (1994, 1996) classification of stream types was only adopted for assessment of stream functioning in selected channel reaches. Specifics of methodology are elaborated below for additional clarity where relevant.

\subsection{Bed material}

As the majority of the channel bed substrate of streams in BTNR is sand and coarse sand, only qualitative observations were recorded except for a few channel reaches where significantly larger bed material was found, e.g. gravel, cobbles, and even boulders. Pebble count was conducted in these channel reaches. A modified version of the Wolman (1954) sampling technique was used for pebble count. Callipers were used to measure the intermediate axis of each particle. Specifics of methodology are elaborated below for additional clarity where relevant.

\subsection{Riparian vegetation}

Riparian vegetation along the two sides of the bank, in a belt extending $10 \mathrm{~m}$ from the water's edge was observed and recorded based on its structure, with values of 1 to 4 representing a range of simple to complex vegetation (1, with no distinct layer of plant; 2, with one of the three layers: understorey, canopy and emergent); 3 , with two of the three layers; and 4, with all three layers present). Canopy cover was measured 
with a densiometer, from four directions; North, South, East and West. Thereafter, the average cover was calculated and multiplied by 1.04 to obtain a percentage of canopy cover.

\subsection{Sediment transport}

The sediment transport capability of various streams was assessed through qualitative observations recorded in the field and followed methods proposed by Galia \& Hradecký (2014b) to evaluate the direct sediment input and occurrence of channel accumulations (if any). Specifics of methodology are elaborated below for additional clarity where relevant.

\section{General observations}

Qualitative observations of characteristics such as basin topography, bank erosion, vegetation, rock outcrops, and channel flow were also made along the length of each channel.

\section{Results and Discussion}

The geology of Bukit Timah is best studied in the various quarries which occur mainly along the western side of the granitic batholith. The hill is entirely on plutonic rocks of granite which is Triassic in age, dated to 217-229 Ma (Lee \& Zhou, 2009). It is unique in Singapore and is representative of the vegetational landscape before anthropogenic alterations. Following the impoundment of the MacRitchie and the Peirce reservoirs that are partly fed by streams from the eastern side of BTNR, expressway and pipeline construction to the east, as well as residential developments in the surrounding areas, the hill cluster is left with forested slopes and headwater valleys, with most of the area above $60 \mathrm{~m}$ elevation. The highest and steepest part consists of a NNW-SSE trending ridge with three peaks above $140 \mathrm{~m}$ separated from each other by steep valleys. The peak reaching $163.6 \mathrm{~m}$ is the highest point in Singapore. The steepness of the slopes controls much of the weathering of Bukit Timah. For example, although soil mantles of up to $10 \mathrm{~m}$ thickness have been observed at quarry excavations on the outskirts of the nature reserve, weathering profiles tend to be thinner on the eastern slopes. The local steepness of the slopes also influences the rainforest structure and is one of the factors resulting in breaks in the canopy (Chatterjea, 1989a, b; Gupta, 1992). Other factors would include tree mortality, storm damage, and past human disturbance.

The streams found within the area are essentially the headwaters of the preexisting drainage systems. At present, the dismembered headwaters drain into Peirce Reservoir via culverts beneath BKE to the east, to concrete storm water channels leading to Sungei Kadut to the north, and Bukit Timah Canal to the south. The lower courses of these headwater streams have been concretised, resulting in the loss of connectivity, making formerly neighbouring branches separate from each other and confined to their respective small catchments. An up-to-date map of streams in BTNR based on the current survey is provided (Fig. 2-5). The summary results for observed parameters of streams, or means for channel-reaches, are given in Table 3. 
Table 3. Basic characteristics of all stream systems in Bukit Timah Nature Reserve and its surroundings. For Rail Corridor and Catchment streams, lengths of the major branches are listed. Total catchment area exceeds the area of BTNR (163 ha) because the streams extend into neighbouring nature parks. Predominant vegetation zones follow definitions and maps in Chan \& Davison (2019); in each case the first listed covers the majority of the respective catchment.

\begin{tabular}{llll}
\hline Stream name & $\begin{array}{l}\text { Approximate stream } \\
\text { length (m) }\end{array}$ & $\begin{array}{l}\text { Catchment area } \\
\text { (ha) }\end{array}$ & Predominant vegetation zones \\
\hline Fern Valley & 750 & 21.81 & Primary; Old Secondary \\
Taban & 250 & 6.87 & Old Secondary; Primary \\
Lasia & 1700 & 65.36 & Maturing Secondary \\
Wallace & 1100 & 37.31 & Maturing Secondary \\
Dairy Farm & 700 & 14.61 & Old Secondary \\
Rail Corridor & $600+200$ & 16.45 & Old Secondary; Maturing Secondary \\
Catchment & $600+500$ & 30.25 & Primary; Old Secondary \\
Seraya & 250 & 3.60 & Primary \\
Jungle Fall & 350 & 7.62 & Primary \\
Asas & 450 & 11.08 & Maturing Secondary \\
\hline Total & & 214.96 & \\
\hline
\end{tabular}

\section{Hydrology}

\subsection{Precipitation/runoff relationship}

Rainfall is the main driver of hydrological processes. Characterising the rainfall variability and processes of runoff generation are critical for understanding the ecosystem functions of catchments. The amount of precipitation that does not soak into the ground and instead runs off the ground surface is a critical component in determining the size of a stream channel. Regions that have high precipitation and runoff (precipitation/runoff) rates typically have larger channels than areas with lower precipitation/runoff rates. A natural channel should carry the appropriate amount of water to maintain dynamic equilibrium and appropriate streambed formations. Singapore's climate is hot and humid equatorial, with no marked dry season. The temperatures vary little throughout the year with an annual average temperature of $27.9^{\circ} \mathrm{C}$ and a mean relative humidity of $84 \%$ in 2018 (Meteorological Service Singapore, 2019). The rainfall is usually greatest in the months of November to January (the north-easterly monsoon) but rain falls in all months of the year, with an average of 167 rainy days in a year. The 1981-2010 long-term mean annual rainfall total is $2165 \mathrm{~mm}$. Much of the rain is accompanied by thunder (Meteorological 
Service Singapore, 2019). Rainstorms are short, intense and generally have a limited spatial extent, with intensities typically ranging between 20 and $50 \mathrm{~mm} / \mathrm{h}$, although short duration (5 min) rainfall intensities can exceed $100 \mathrm{~mm} / \mathrm{h}$ (Sherlock et al., 2000). During their field study conducted in 1993, Sherlock et al. (1995) recorded 15-minute intensities of up to $111 \mathrm{~mm} / \mathrm{h}$ in the Jungle Fall catchment. Chatterjea (1989b) reported slightly higher 15 -minute intensities of $120 \mathrm{~mm} / \mathrm{h}$ on Bukit Timah. Both records are close to a return period of two years (Public Utilities Board, 2013).

\subsection{Throughfall, stemflow and evapotranspiration}

The forest in Bukit Timah is a combination of continuous understorey and main canopy, scattered emergent trees, and gaps at treefalls, rock outcrops, recent landslide sites, and places with very steep slopes. The canopy acts as an interceptor to the rain but a proportion, which can be substantial when the rainfall is heavy, passes directly through the gaps (Gupta, 1992). Chatterjea (1989a) compared the rainfall recorded in the Bukit Timah carpark with readings from gauges set under the trees. For a total of 35 rainstorms monitored, the throughfall was $57.8 \%$ of the total rainfall on average, the percentage ranging between $0 \%$ and $91.3 \%$. No throughfall was recorded if the rain event was less than $2 \mathrm{~mm}$.

The sum of evaporated intercepted rain water, transpired water from the canopy foliage and bark surfaces, and evaporation from the ground surface is termed evapotranspiration. Greater evapotranspiration results in less water being available for soil water drainage and streamflow. As with the canopy interception, throughfall and stemflow percentages, evapotranspiration (ET) measurements across the humid tropics exhibit a huge range, 35 to 62 per cent in Southeast Asia (Sherlock 1997). Sun et al. (2016) used reference ET data from the MOD16 Global Terrestrial Evapotranspiration Data Set and estimated the 2012 reference ET to range from 65 to $140 \mathrm{~mm} / \mathrm{month}$ with an average of $100 \mathrm{~mm} / \mathrm{month}$ for Nee Soon freshwater swamp forest, which approximately corresponds to a range of 34 to 73 per cent of the rainfall in Singapore. Based on the vegetation type, the ET in Bukit Timah may be estimated to be close to the lower range of that in Nee Soon.

More water reaches the ground via stemflow. Although a substantial amount of the rainfall on top of canopy is evaporated back to the atmosphere, when the rain is heavy and/or continuous water tends to run down the trunks of the large trees to the forest floor. This is a common phenomenon in the rain forest (Manokaran, 1979), but in this part of the world the rain has to be at least $5 \mathrm{~mm}$ for the stemflow to make any significant contribution (Chatterjea, 1989a; Gupta, 1992).

\subsection{Subsurface stormflow}

The soil surface in undisturbed tropical rain forest environments characteristically has a well-developed litter layer overlying a dense root mat. Intense biological activity, which serves to incorporate organic matter into the topsoil, and the high root density in the surface soils generally results in high infiltration rates (Sherlock, 1997). Horton (1933) proposed that storm-period streamflow was dominated by overland flow, which develops as a result of rainfall intensities exceeding the infiltration capacity of the soil. This mechanism is regarded as being more applicable to arid zones or urbanized areas where soils can exhibit 'hydrophobicity'. Hewlett \& Hibbert (1967) believed 
that all rainfall infiltrates into the ground in natural (vegetated) humid catchments, even during the most prolonged and intense storm events. Any observable overland flow is a product of either rainfall falling onto, or return flow (exfiltrated soil water) from upslope flowing over, already saturated areas. Whilst saturation is maintained at the soil surface, overland flow occurs regardless of rainfall intensity. Saturation-excess overland flow is most commonly observed over expanding and contracting saturated riparian areas during rainfall (Sherlock, 1997).

Field experiment used tracer inputs at the soil surface of two gradient slots $\left(15^{\circ}\right.$ plot and $27^{\circ}$ plot) in Jungle Fall Valley followed a predominantly vertical flow pathway to at least $0.7 \mathrm{~m}$ depth (Sherlock et al., 1995; Sherlock,1997; Chappell \& Sherlock, 2005). Working within a different catchment in the Taban Valley, Chatterjea (1989a, 1989b; 1994) also identified near-surface saturation (upper $28 \mathrm{~cm}$ of the profile) following rainfall, while the subsoil remained unsaturated. However, in contrast to the observations in the Jungle Fall catchment of Sherlock (1997), Chatterjea (1989b) reported that when the upper profile attained saturation, "on occasions" saturation overland flow was apparent. "On no occasion was saturation or infiltration excess overland flow evident within either the $15^{\circ}$ or the $27^{\circ}$ plots, or in any other zones of the Jungle Falls catchment (Sherlock (1997)". As such contradicting hillslope flow process observations are apparent at such a local scale, e.g. those of Chatterjea (1989a, 1989b; 1994) and Sherlock (1997), this would suggest that either very different soil hydraulic properties exist between the two catchments, or that the storms which produced overland flow in Chatterjea's study had greater magnitudes than the storms which occurred during the field season of Sherlock (1997). Overland flow was not observed in the Jungle Fall catchment during one very large storm in April 1993, which comprised $111.7 \mathrm{~mm}$ total rainfall and a peak 10-minute intensity of $111.2 \mathrm{~mm} / \mathrm{h}$ (a magnitude suggesting an approximately 2-year return period), which would suggest that the difference in hydraulic soil properties between the Jungle Fall and Taban Valley catchments is the cause of the apparently contrasting runoff mechanisms.

The infiltration capacity data presented indicate that, typically, these tropical forest topsoils are very permeable, suggesting that the hydrological processes will be dominated by subsurface flow pathways. Hortonian or infiltration-excess overland flow should therefore be minimal. Sherlock (1997) found that in Jungle Fall valley, which has Ferric Acrisol topsoil with relatively high permeability, there was a 90:10 split of vertical to lateral tracer flow.

The subsurface runoff is likely to be facilitated by the presence of natural pipes within the soil. Chappell (2010), in a review of the distribution and hydrological function of soil pipes, commented that of the studies reporting the presence of soil piping within the humid tropics, most are associated with Ultisol soils, and, locally, most pipe outlets are observed on the lower sections of hillslopes. Natural soil pipes have previously been documented from BTNR by Sherlock (1997) and Chatterjea (1989a) with diameters of $10 \mathrm{~cm}$ and 2-8 cm respectively.

\subsection{Surface runoff}

The runoff at the ground surface is shallow (a few $\mathrm{mm}$ in depth), widespread, and usually hampered by ground litter and tree roots. Chatterjea (1994) documented that in Bukit Timah, "localised overland flow develops at the tree bases owing to stemflow 
during intense rainstorms. Although stemflow was not measured for this study, signs of such flows were seen in the tree-base scours and lack of litter cover at the downhill side of the tree trunks" and "the combined effect of saturation overland flow and point source development of infiltration-excess surface runoff is seen during rainstorms when widespread unconcentrated overland flow, varying in depth from 2 to $10 \mathrm{~mm}$, develops in the forest. Widespread development of rootsteps on the Bukit Timah forest slopes is evidence of overland flow generation" (Chatterjea, 1994). At times, rain falling directly onto a slippery mat of leaf litter on the ground is quickly transformed into surface runoff, but in general surface runoff is brief, the water disappearing underground or into vegetated swales almost as quickly as it began. The upper horizon interflow persists longer, and in the forest often the water is conveyed efficiently through natural pipes in the subsurface material (Chatterjea, 1994).

\subsection{Rainfall vs. discharge}

Based on the above discussion, the rainfall to stream flow progression goes through a complicated slope-related hydrological process and the travelling time for different raindrops may vary substantially. However, limited records of discharges in Fern Valley stream and Jungle Fall stream seem to indicate that in general, stream flow in BTNR corresponds well with the rainfall pattern, with stream discharge normally responding within one to two weeks of lag time, though stream flow varies as expected with localised rainfall (Nguyen \& Cai, 2019). This is probably owing to the small catchment area where the groundwater table relies on the regular recharge of vertical subsurface storm flow to maintain its level, which, in turn, regularly exfiltrates to form the baseflow of the stream channel.

\section{Hydraulics}

\subsection{Drainage density}

The drainage density is a measure of how well a catchment is drained. It depends upon both climate and physical characteristics of the drainage basin. In a small hill like that of BTNR, the climate conditions should be more or less the same throughout. The drainage density calculated for each catchment (Fig. 6) shows that all are roughly comparable, from $34.2 \mathrm{~m} /$ ha (Wallace stream catchment) to $74.2 \mathrm{~m} /$ ha (Seraya stream catchment). The differences could be caused by local variation in physiogeomorphic characteristics. The majority of the streams in BTNR are of order 1, with only one order 3 stream (Lasia stream), and three order 2 streams (Catchment, Dairy Farm and Rail Corridor streams). On the upper slopes, not all channels carry water for any length of time especially for the segments that are located at the uppermost channel. The channels are meandering in pattern with sand though the sinuosity is low (1.0-1.3, mode 1.1), with a mean water depth ranging from 4.2 to 6.6 $\mathrm{cm}$.

\subsection{Flow dynamics}

The water flowing downhill along a stream channel is affected by gravity and the channel gradient. The flow is retarded by resistance from the stream bed and banks. The interaction of flowing water against the stream bed and banks creates dynamic 
flow conditions. The morphology of natural channels is dependent on these flow dynamics. In intermittent and perennial streams like those found in Bukit Timah, the discharge of groundwater and the overall surface/subsurface interaction creates additional functions, especially as they relate to and support physicochemical and biology functions.

\subsubsection{Stream velocity and stream power}

Knighton (1998) describes stream velocity as one of the most sensitive and variable properties of open-channel flow because it is dependent on a wide range of factors, and it influences the erosion, sediment transport and deposition of the stream channel. Stream velocity is important at both baseflow and flood flow conditions. High baseflow velocities may prevent upstream movement of aquatic animals, and high floodflow velocities can cause stream bed and bank erosion if the flow force exceeds the resisting forces. Therefore, stream velocity is a widely used parameter to help assess channel stability, create stable channel designs when modified, and help support aquatic life. Velocity can also be measured in the field; this is easier to do during baseflow conditions than bank-full or flood conditions. Baseflow of the BTNR streams is relatively slow, with average ranges from $0.025 \mathrm{~m} / \mathrm{s}$ (Seraya stream) and $0.05 \mathrm{~m} / \mathrm{s}$ (Jungle Fall stream) to $0.141 \mathrm{~m} / \mathrm{s}$ (Asas stream) and $0.127 \mathrm{~m} / \mathrm{s}$ (Fern Valley stream). The average stream velocity is given in Table 4 , and the quartile chart of velocity in each stream is presented in Fig. 7, indicating very low flow velocities (mean $0.127 \pm 0.013$ $\mathrm{m} / \mathrm{s}$, ranging from $0.01 \mathrm{~m} / \mathrm{s}$ at stream heads SR7, LS 17 to $0.428 \mathrm{~m} / \mathrm{s}$ at LS1 and mean stream power ranges of $0.029 \mathrm{~W} / \mathrm{m}^{2}$ ) at the uppermost reach of the Dairy Farm stream (DF 13), to $7.54 \mathrm{~W} / \mathrm{m}^{2}$ at the outlet of Catchment stream (CS1).

However, at bank-full conditions, the stream velocity can increase dramatically (Table 5). The projected bank-full velocity in the lower reaches of Fern Valley (FV2, 3), Lasia (LS4,5,7,8,10), Catchment (CS1), Wallace (WL1) and Rail Corridor (RC 7) streams can be raised to 29 times their baseflow velocity. In an extreme case at Rail Corridor (RC7) mean stream power is projected to rise enormously, by more than 100 times, from 1.587 to $179.36 \mathrm{~W} / \mathrm{m}^{2}$.

Though most kinetic energy from stream power is dissipated through friction from the bed and banks, a small portion remains and performs geomorphic work like the entrainment and transport of sediment. As a functional assessment tool, mean stream power is more useful than cross-sectional stream power. This is because mean stream power is normalized by channel width and can be compared across various streams of different size (Harman et al., 2012).

\subsubsection{Flow duration}

Flow duration can be generalised to focus on the simple presence versus absence of flow over time, e.g. perennial, intermittent or ephemeral streams. When flows are critical to maintain a particular species of fish, shrimp or crab (Khoo et al. 2019; Li et al., 2019), flow duration curves can allow one to denote the percentage of time that a river will exceed the critical value. Flow duration curves are not available for streams in BTNR. Based on field work in BTNR over the last eight years, we have observed that the stream lines shown in blue from the current mapping work (Fig. 2) indicate the perennial channels in the various streams, though the water volume could be quite 


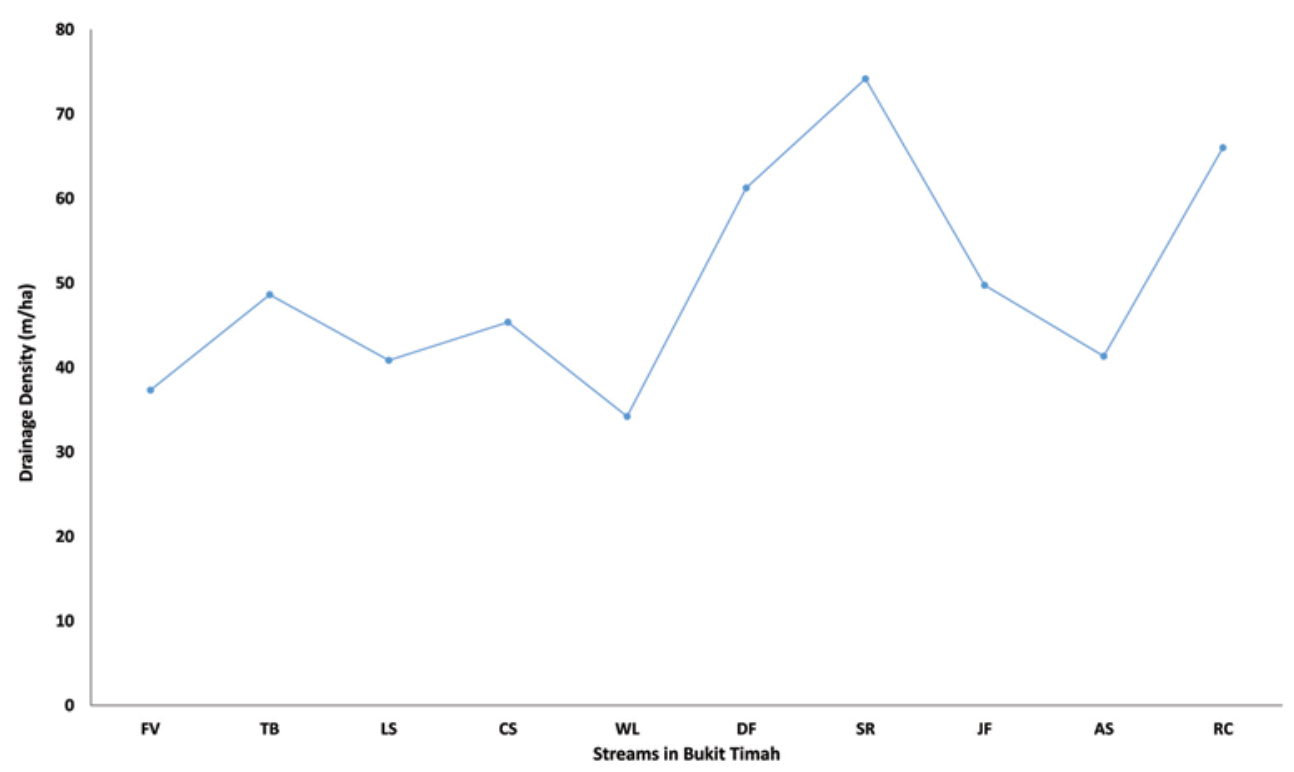

Fig. 6. Drainage density of various catchments in Bukit Timah.

variable. However, during the driest period in January-February 2014, some of the colluvial reaches in the upper parts of Wallace, Dairy Farm and Taban streams do not show discernible surface flow, only a very little water running beneath the surface under gravel, leaf litter and wooded debris.

\subsubsection{Floodplain connectivity}

Floodplain connectivity describes how often streamflows access (or spill over into) the adjacent floodplain. In high-functioning alluvial valleys, all flows greater than the bank-full discharge spread across a wide floodplain. In humid environments, streams that are well connected to the floodplain also have relatively high water tables, encouraging the development of riparian wetlands. In these systems, the channel is just deep enough to maintain sediment transport equilibrium and to create diverse bed forms and habitats (Harman et al., 2012).

The majority of channel reaches in BTNR have a Bank Height Ratio (BHR) between 1.0 and 1.2, and an Entrenchment Ratio (ER) of more than 2.2, which indicates that these channels are functioning well with good floodplain connectivity. However, a few reaches on the lower slopes are functionally at-risk, with either BHR between 1.3 to 1.5 or ER 1.2 to 1.4 (B type streams), if the criteria of Harman et al. (2012) are applied (Table 6). These at-risk channels are located at LS8 (BHR 1.4) and LS10 (ER 1.30). Two channel reaches examined at lower Fern Valley, namely FV2 (BHR 3.41, ER 1.73) and FV3 (BHR 3.69, ER 1.39); two at lower Lasia Stream, namely LS5 (BHR 1.9, ER 1.7) and LS 4 (BHR 1.5), one at lower Wallace Stream, WL1 (ER 1.43), one at Rail Corridor, RC7 (BHR 3.0), one at Dairy Farm Stream, DF9 (BHR 3.0, 1.6), are all not functioning as to floodplain connectivity, resulting in channelisation. 
Table 4. Characteristics of streams in Bukit Timah hill, including Bukit Timah Nature Reserve and surrounding nature parks.

\begin{tabular}{llllll}
\hline Stream & $\begin{array}{l}\text { Survey } \\
\text { sites }\end{array}$ & $\begin{array}{l}\text { Elevation } \\
(\mathbf{m})\end{array}$ & $\begin{array}{l}\text { Channel gradient } \\
\mathbf{( \% )}\end{array}$ & $\begin{array}{l}\text { Dominant } \\
\text { bedload }\end{array}$ & $\begin{array}{l}\text { Direct Sediment } \\
\text { Input }\end{array}$ \\
\hline Fern Valley & 7 & $41-150$ & $5.69(2.08-14.2)$ & Sand/gravel & 1.86 \\
Taban & 4 & $46-88$ & $6.16(5.42-6.7)$ & Sand/silt & 1.50 \\
Lasia & 17 & $37-142$ & $6.78(0.36-29.7)$ & Sand/silt & 1.47 \\
Catchment & 17 & $50-137$ & $6.83(0.8-11.48)$ & Sand/silt & 1.06 \\
Wallace & 6 & $43-98$ & $5.44(0.88-12.89)$ & Sand/gravel & 2.17 \\
Dairy Farm & 7 & $42-110$ & $5.20(1.24-7.24)$ & Sand/cobble & 2.14 \\
Seraya & 5 & $118-144$ & $5.72(2.44-9.5)$ & Sand/silt & 1.20 \\
Jungle Fall & 7 & $126-158$ & $5.78(2.3-10.96)$ & Sand/boulder & 1.00 \\
Asas & 6 & $40-68$ & $2.53(1.56-3.92)$ & Sand/cobble & 1.17 \\
Rail Corridor & 8 & $45-97$ & $2.98(0.83-5.28)$ & Sand/silt & 1.13 \\
\hline
\end{tabular}

\begin{tabular}{llllllll}
\hline Stream & $\begin{array}{l}\text { Oc Ch } \\
\text { acc }\end{array}$ & $\begin{array}{l}\text { Woody } \\
\text { Debris }\end{array}$ & $\begin{array}{l}\text { Wet depth } \\
(\mathbf{m})\end{array}$ & $\begin{array}{l}\text { Wet width } \\
(\mathbf{m})\end{array}$ & $\begin{array}{l}\text { Flow rate } \\
\left(\mathbf{m}^{\mathbf{3}} \mathbf{s}\right)\end{array}$ & $\begin{array}{l}\text { Discharge } \\
(\mathbf{l} / \mathbf{s})\end{array}$ & $\begin{array}{l}\text { Canopy Cover } \\
(\%)\end{array}$ \\
\hline Fern Valley & 2.00 & 2.00 & 0.060 & 0.840 & 0.127 & 8.36 & 75.0 \\
Taban & 2.00 & 1.75 & 0.045 & 1.395 & 0.072 & 5.49 & 84.8 \\
Lasia & 1.71 & 1.76 & 0.066 & 0.991 & 0.111 & 75.38 & 88.1 \\
Catchment & 1.06 & 2.24 & 0.053 & 0.678 & 0.056 & 9.88 & 83.9 \\
Wallace & 2.00 & 1.50 & 0.042 & 1.009 & 0.106 & 15.45 & 85.5 \\
Dairy Farm & 1.71 & 2.57 & 0.049 & 0.596 & 0.110 & 5.13 & 84.6 \\
Seraya & 1.40 & 2.20 & 0.048 & 0.620 & 0.025 & 0.46 & 86.7 \\
Jungle Fall & 1.57 & 2.14 & 0.046 & 0.853 & 0.050 & 2.09 & 89.6 \\
Asas & 1.17 & 1.33 & 0.056 & 1.407 & 0.141 & 24.45 & 85.0 \\
Rail Corridor & 1.25 & 1.25 & 0.065 & 0.771 & 0.060 & 5.06 & 84.5 \\
\hline
\end{tabular}

Channelisation is the primary impact that has directly disconnected streams from their adjacent floodplain. Schoof (1980) defines channelisation as the widening, deepening and straightening of channels to increase their capacity for transporting flood flows and to decrease flooding on adjacent land. The primary effects of channelisation include reduction in stream length through straightening; the lowering of groundwater levels; reduction of groundwater recharge from stream flow; increase in erosion and sedimentation; and increase in downstream flooding. A combination of several such factors may cause channelisation but, based on current observations, the combination of higher stream power released by the higher gradient of the upper stream reaches, and locally erosible soil are the two factors most responsible.

The indirect impacts, such as increases in impervious cover, also contribute to channel enlargement and incision through increased runoff. The extra runoff 


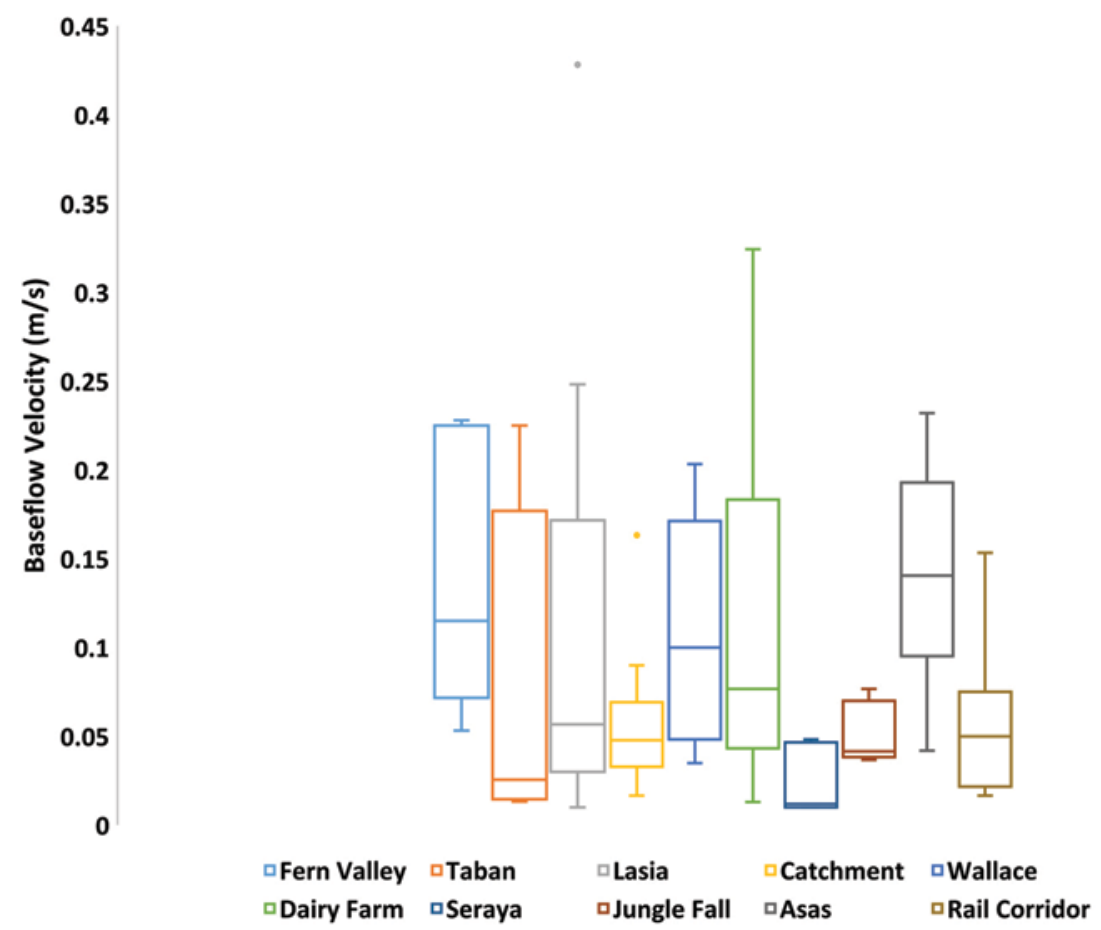

Fig. 7. Quartile chart of baseflow velocity $(\mathrm{m} / \mathrm{s})$ of streams in Bukit Timah.

often causes an increase in stream power, which leads to headcuts and incision. The combination of increased runoff and channelisation can lead to rapid destabilization and adjustment of stream channels.

\subsubsection{Groundwater/surface water exchange}

Surface water in streams interacts with groundwater in three basic ways: groundwater discharging into the stream through the stream bed (gaining stream), surface water percolating through the bed and into groundwater (losing stream), or a combination of both (Winter et al., 1998). Gaining streams are characterised as zones where the water table is higher than the stream bed. Losing streams are the areas where the water table is below the elevation of the stream bed. In Bukit Timah streams, surface and groundwater exchange is quite variable. Most stream reaches show a trend of increasing discharge along the channel from the stream head, downslope to the outlet, but with some of the reaches in between disrupting this general trend.

For example, in Fern Valley, the stream flows down from its head through a hyporheic zone (a region beneath and alongside the stream bed, where there is mixing of shallow groundwater and surface water) which is more than $100 \mathrm{~m}$ in length, running through crevices between outcrop and boulders. The stream is probably receiving from and at the same time recharging to the groundwater table, keeping more or less the same overall discharge. Then, the stream increases its discharge significantly before running down a high gradient boulder slope. The channel becomes deeper and wider, meandering within a distinctive sigmoid channel segment towards the lower 


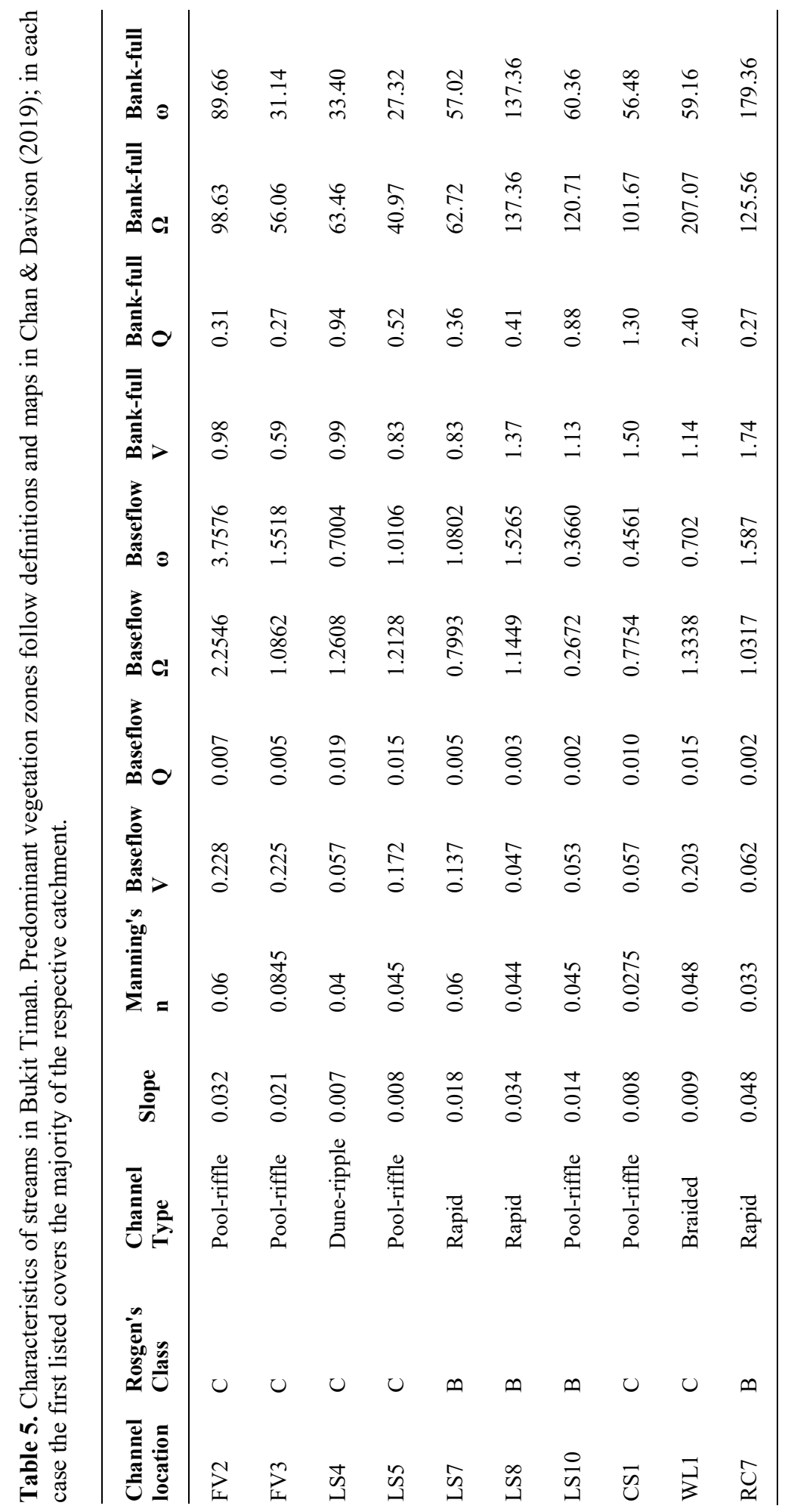




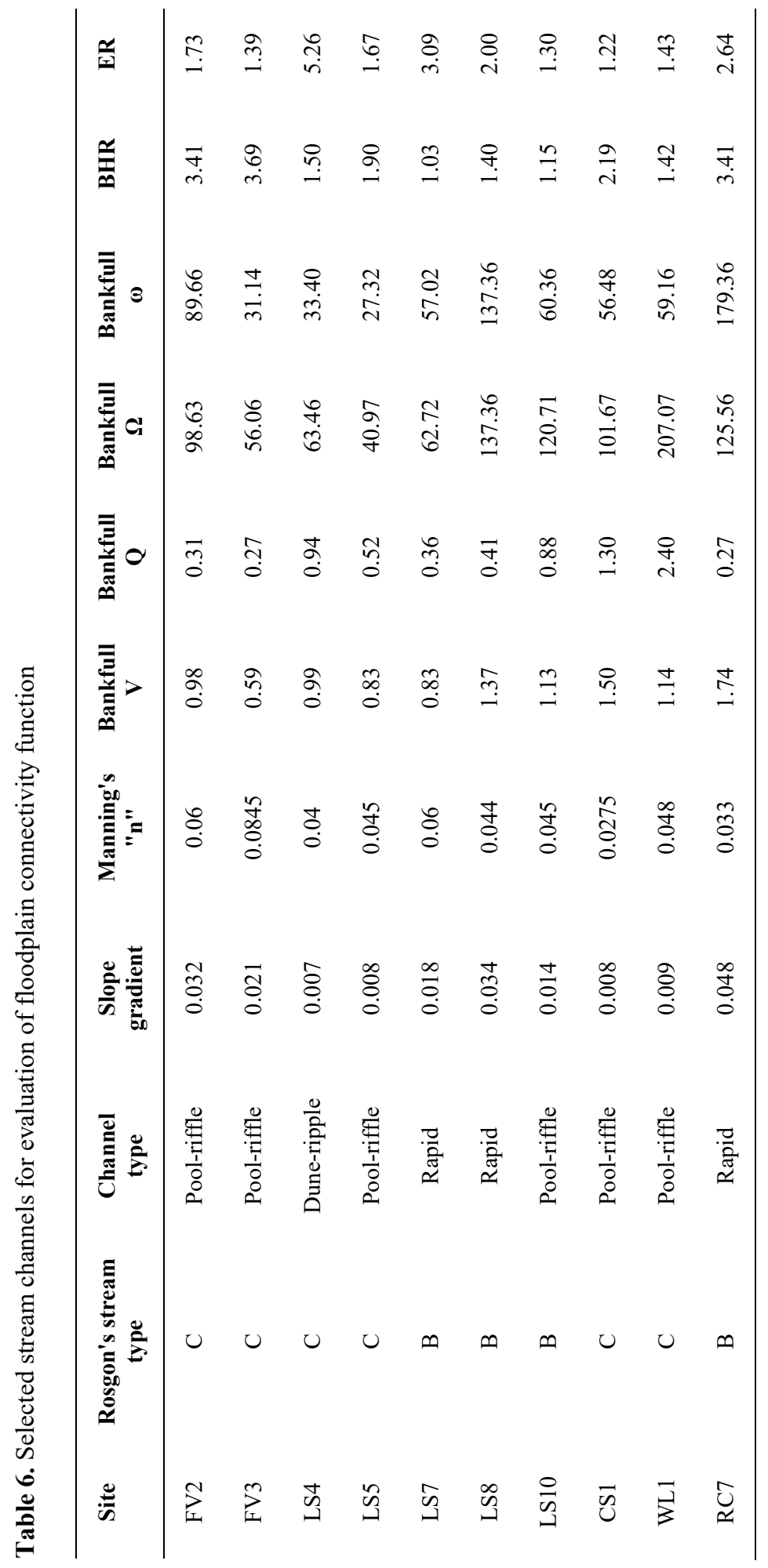


reaches. A significant loss of water was found corresponding to this downslope movement, the stream discharge dropping from $8.78 \mathrm{l} / \mathrm{s}$ at FV4 to $5.32 \mathrm{1} / \mathrm{s}$ at FV3 (Fig. 8). Thereafter, the discharge increased accordingly. Compared against groundwater level data collected from three stations (Lower, Mid, and Upper) along the Fern Valley (Table 7; S.Y. Liong, pers. comm.), the Mid station show a significantly lower mean groundwater level $(-1.381 \mathrm{~m}$ versus $-0.889 \mathrm{~m}$ at the upper valley; and $-0.889 \mathrm{~m}$ at the lower valley), which coincides with the surface water discharge pattern during the survey period.

The Jungle Fall stream also shows a distinct drop in discharge at its middle reaches (between JF 4 and JF5: Fig. 9); unfortunately, groundwater data are not available for the Midstream though the data from the two wells located at Lower and Upper reaches of the stream have a similar mean groundwater level.

\section{Geomorphology}

\subsection{Longitudinal profile}

The longitudinal profile of each stream is plotted in Fig. 10, from the highest point of the stream channel, to give a general impression of the stream line variation in distance and relief. The longitudinal profiles of all the streams in BTNR are generally concave, with steeper upper reaches and shallow gradient lower reaches, except for Jungle Fall and Seraya streams which display a slightly convex form. In between, one or two distinct knickpoints can be observed in several streams at locations close to the base of the hill. These knickpoints are interpreted as representing the transition from debris-flow dominated colluvial channels to stream-flow dominated fluvial channels. Jungle Fall and Seraya streams on the upper slopes of the hill, with a convex profile, represent two upper branches of what must formerly have been a continuous stream system before Singapore Quarry started its operations in the early 1900s.

\subsection{Channel head}

The channel head, or channel initiation, the most upstream point, marks the beginning of fluvial erosion processes on the hill slope, and determines the degree of landscape dissection. Field studies of channel initiation have viewed it as a geomorphic threshold controlled by slope, drainage area, and climate (Montgomery \& Dietrich, 1988). Although a channel head can be present on a planar slope, channel heads typically occur within hillslope concavities that serve to concentrate surface and subsurface water flow sufficiently to create channel erosion.

The channel heads in the Bukit Timah area have various magnitudes of contributing area (5000-17,200 $\mathrm{m}^{2}$ ), and average gradient of slope above the channel head ranging from 10.25 to $-24.89 \%$. Fig. 11 shows the relationship between the contributing area $\mathrm{A}$, and the slope gradient above the channel heads. Least squares regression analysis on log-log scale plots yields a negative correlation between $\mathrm{A}$ and $\mathrm{S}$ :

$$
A=6.475 S^{-0.145}
$$




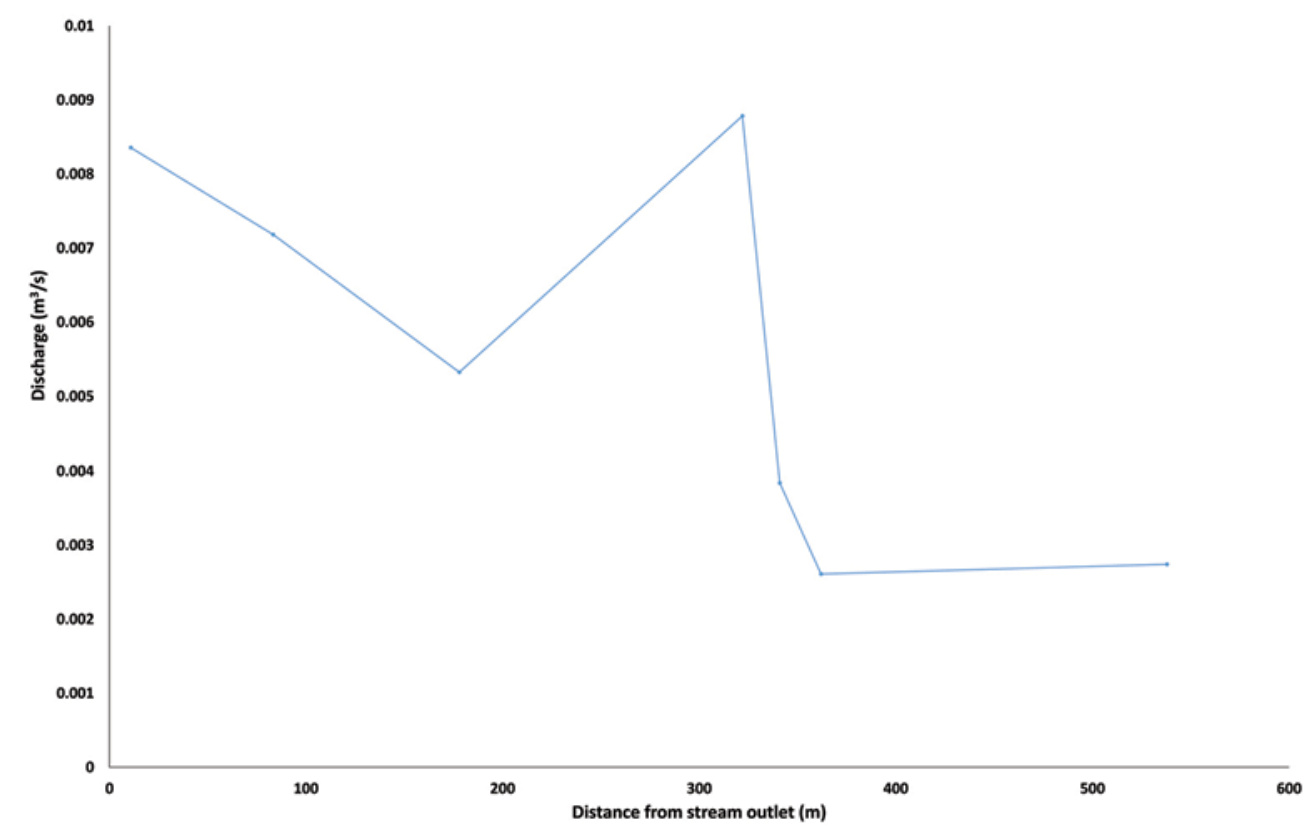

Fig. 8. Average discharge in different channel reaches of Fern Valley stream.

Table 7. Groundwater levels at Fern Valley and Jungle Fall (Liong S.Y., pers. comm.).

Distance of groundwater table to ground surface (m)

\begin{tabular}{llcccc} 
& & Min & Max & Mean & Period \\
\hline Fern Valley & Up & -1.07 & -0.758 & -0.889 & 11 Nov 2017 - 9 May 2018 \\
& Mid & -1.4 & -1.36 & -1.381 & 11 Nov 2017 - 9 May 2018 \\
& Low & -0.965 & -0.477 & -0.832 & 11 Nov 2017 - 9 May 2018 \\
Jungle Fall & Up & -1.572 & -1.235 & -1.351 & 5 Nov 2017 - 9 May 2018 \\
& Low & -1.891 & -1.21 & -1.368 & 5 Nov 2017 - 9 May 2018 \\
\hline
\end{tabular}

Coefficient of determination in the relationship between A and S (R2 = 0.033) shows that the inverse relationship is weak, which implies that locally, as is representative of areas in the moist tropics, various factors such as shallow landslides, substrate erosion following overland flow, and locally significant subsurface stormflow (Sherlock, 1997; Chappell \& Sherlock, 2005) may play a major role in initiation of the channel heads. In addition, however, slope averaged over a part of the catchment might not be an accurate reflection of the micro-topography. 


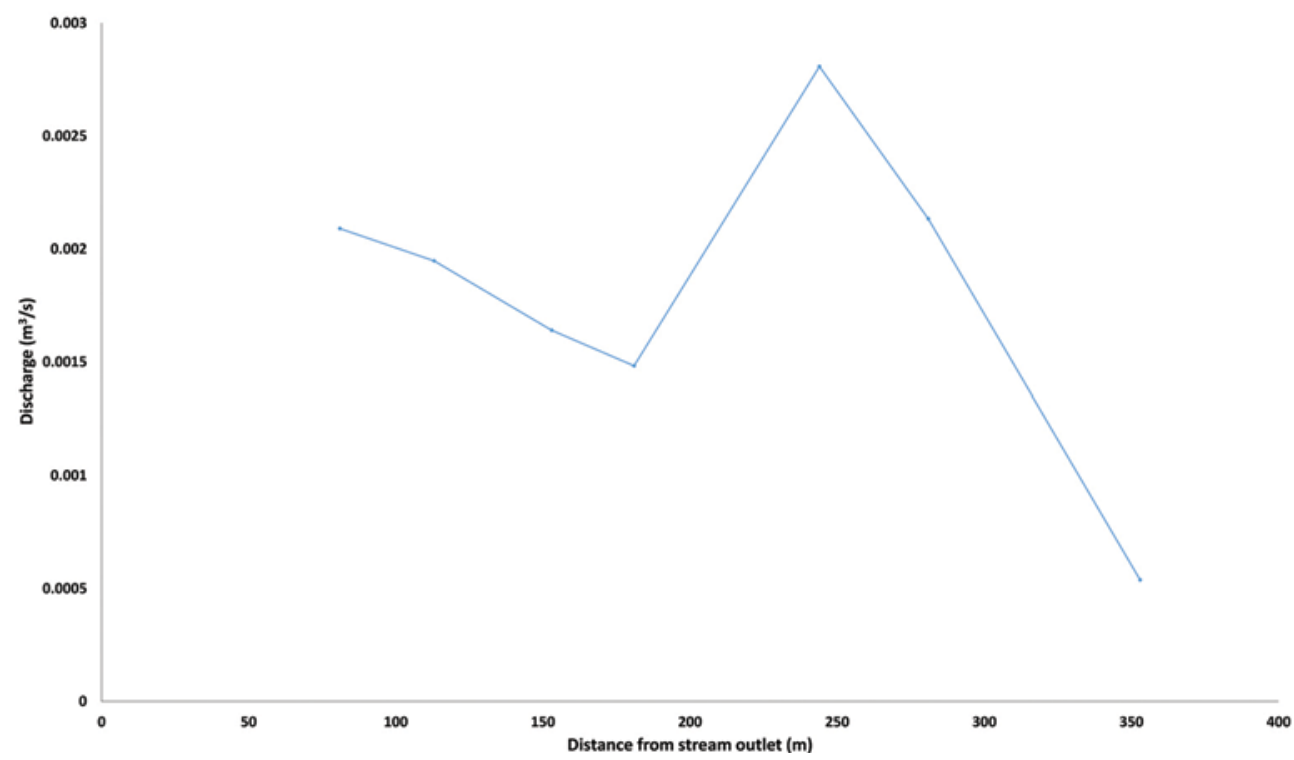

Fig. 9. Average discharge in different channel reaches of Jungle Fall stream.

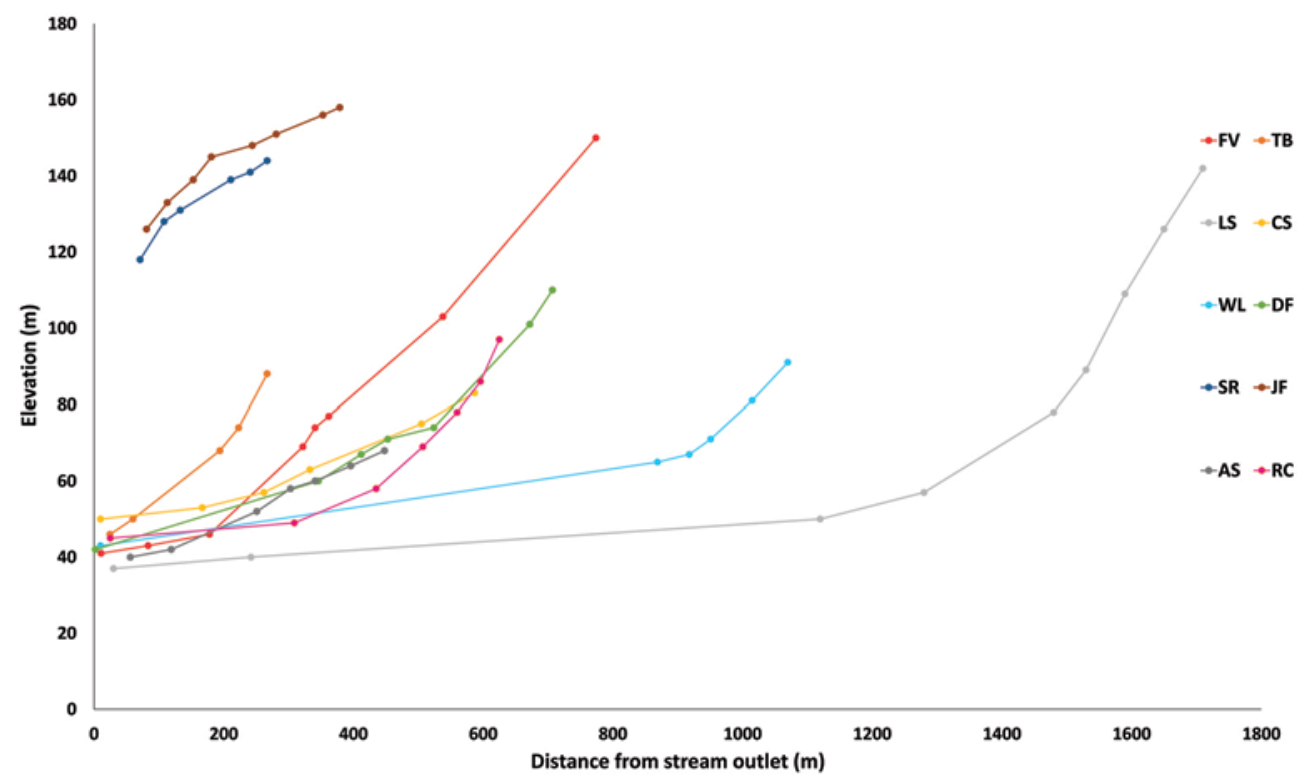

Fig. 10. Longitudinal profiles of streams in Bukut Timah.

\subsection{Channel morphology}

Stream morphology is determined by the interaction between the force exerted by the water and the streambed and bank resistance that are related to streambed material and bedforms (Galia \& Hradecký, 2014a). As a result of those complex processes, channels have different geometric shapes (Leopold \& Maddock, 1953). Undisturbed 


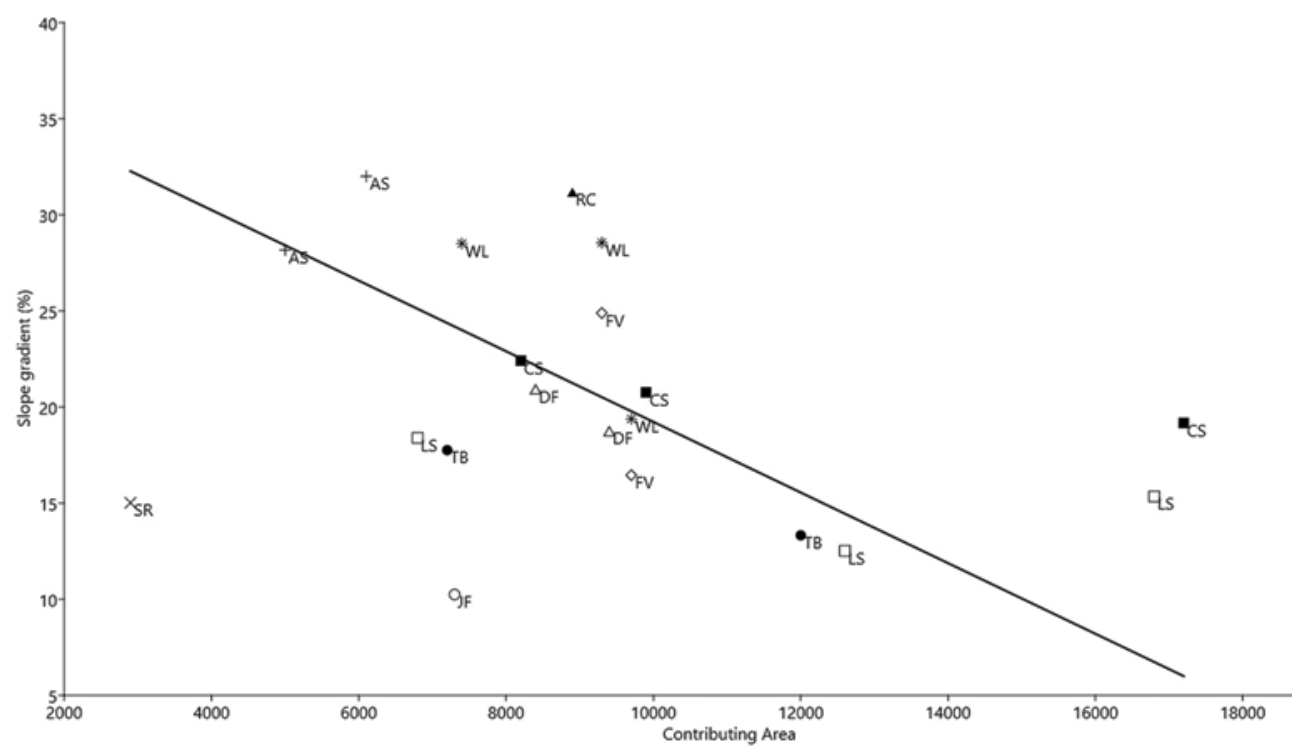

Fig. 11. Plot of contributing area regressed on upslope gradient for channel heads in Bukit Timah.

streams adjust their morphology to dominant discharges that are characterised by maximum sediment transportation during relatively moderate flow events rather than large flow events. This is due to the fact that moderate flows occur much more frequently than high magnitude floods (Wolman \& Miller, 1960). In channels controlled by fluvial processes at or near dynamic equilibrium, dominant discharge is approximately equal to the bank-full discharge (Knighton, 1984; Leopold et al., 1964).

Montgomery \& Buffington (1997) proposed a process-based classification system which could be easily used, based on visual assessment. Results of this assessment could be used to infer the process and functions performed along the reach. They recognised three primary channel-reach substrates: bedrock, alluvium, and colluvium. Bedrock reaches lack a contiguous alluvial bed and reflect high transport capacities relative to sediment supply; they are typically confined by valley walls and have steep slopes. In contrast, alluvial channels exhibit a wide variety of morphologies and roughness configurations that vary with slope and position within the channel network, and may be either confined, with little to no associated floodplain, or unconfined, with a well-established floodplain. They recognised five distinct alluvial reach morphologies: cascade, step-pool, plane bed (rapid), pool-riffle, and dune ripple. Additionally, forced morphology channel was also recognised as a distinct channel type, formed by woody debris or anthropogenic activities (e.g. forced step-pool, forced pool-riffle, etc.) Colluvial channels form an additional reach type that is recognised separately from alluvial channels, despite the common presence of a thin alluvial substrate. Colluvial channels typically are small headwater streams that flow over a colluvial valley fill and exhibit weak or ephemeral fluvial transport. 
The classification of alluvial channels was extended by Galia \& Hradecký (2014a) with bedrock-cascade and step-rapid morphological units. Diagnostic features of each channel type found in BTNR are summarised below. Each of these channel types is distinguished by a distinctive channel-bed morphology, allowing rapid visual classification. In BTNR, step-pool, bedrock-cascade and dune ripple types were not found.

\subsection{Colluvial (Fig. 12A).}

Streamflow may be perennial or ephemeral, with streambeds characterized by poorly sorted sand- to boulder-sized sediment, and bed morphology is strongly controlled by stochastically occurring obstructions (boulders, wood, in-channel vegetation). Steep channel gradients, but little scouring energy because of shallow stream flows and in-channel obstructions that are large relative to channel size. Directly coupled to confining hillslopes. Prone to mass wasting and bulking debris flows (Montgomery \& Buffington, 1997). Shallow and ephemeral flow in colluvial channels appears insufficient to mobilise all of the colluvial sediment introduced to the channel, resulting in significant storage of this material (Dietrich \& Dunne, 1978; Dietrich et al., 1982; Benda, 1990). Out of the 84 channel reaches surveyed in BTNR, 23 are colluvial channels, with gradients ranging from 0.93 to $16.55 \%$. All of them occur immediately next to channel heads.

\subsection{Bedrock (Fig. 12B).}

Typically confined, steep reaches lacking a persistent or continuous alluvial bed due to bed load transport rate greater than sediment supply or due to the recent occurrence of debris-flow scour. Pools and flow obstructions may occasionally retain alluvial pockets of irregular extent and depth (Buffington \& Montgomery, 2013). Only three bedrock reaches were recognised in our survey, which form the distinct knick points distinguishing high gradient upper stream reaches from much gentler and lower stream reaches for Lasia stream and Catchment stream respectively.

\subsection{Cascade (Fig. 12C).}

Chaotic arrangement of boulder-sized bed material can be seen, resulting in continuous macroscale turbulence. The channel is typically confined by valley walls and directly coupled to hillslopes. Steep gradients and concentrated flow allow efficient transport of cobble-sized to sand-sized sediment during annual floods, but movement of the channel-forming boulders requires infrequent large floods. High mobility of the median grain size at bank-full flow. Little sediment storage due to the shallow depth to bedrock and lack of floodplain development. Infrequent, turbulent pools of small volume. Channel gradient is generally more than $7.5 \%$ (Buffington $\&$ Montgomery, 2013). Only two cascade channel reaches were found in the current survey, one at the middle section of Fern Valley stream, and the other at the lowest part of the Jungle Fall stream. Both have very high channel gradient (8.7-8.9\%) and form distinct knick points in the stream profile. 


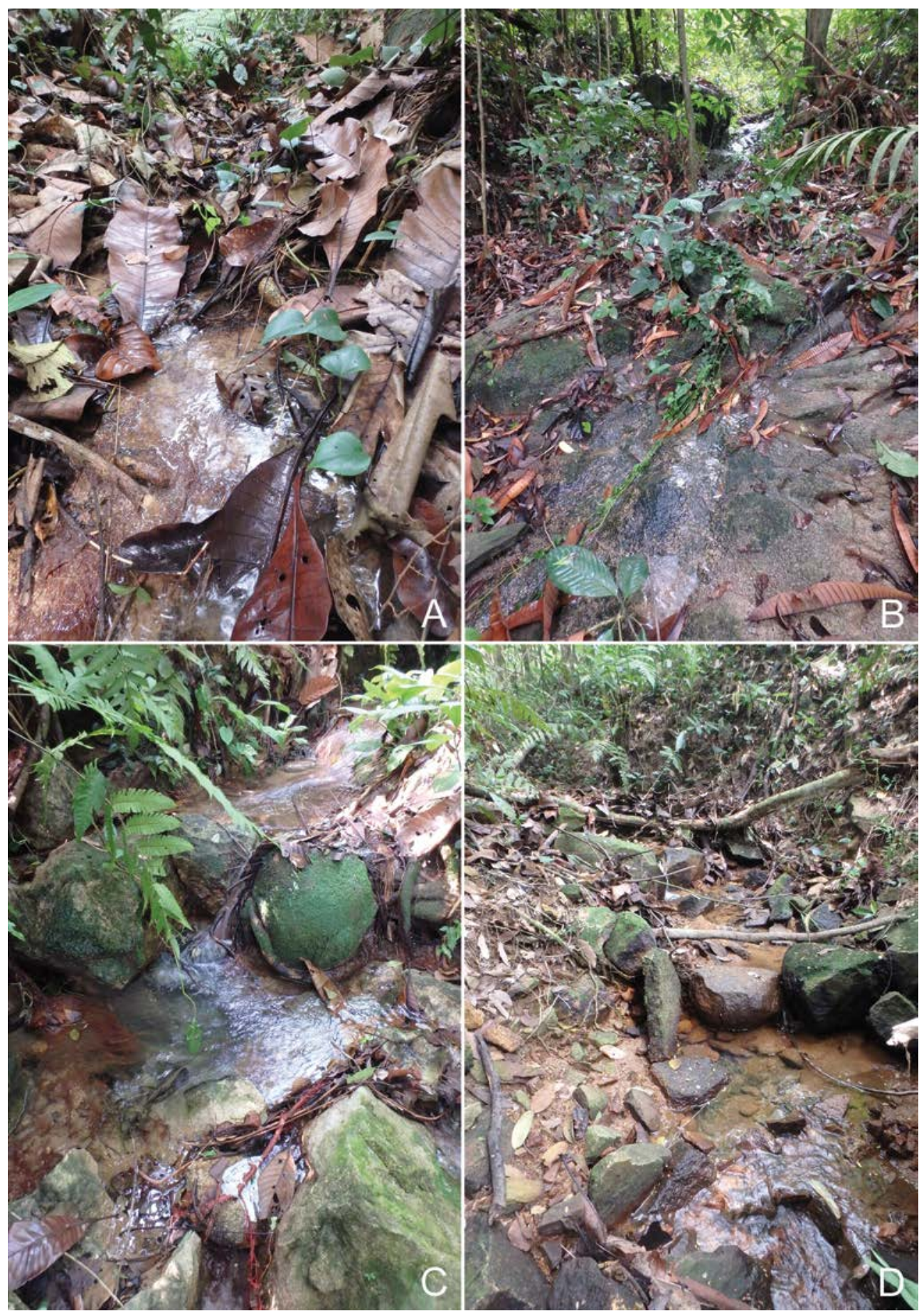

Fig. 12. Channel morphology. A. Colluvial, Wallace stream. B. Bedrock, Catchment stream. C. Cascade, Fern Valley stream. D. Step-rapid, Dairy Farm stream. (Photos: Y. Cai) 


\subsection{Step-rapid (Fig. 12D).}

Step-rapid morphology occupies channel gradients ranging from 4 to $12 \%$, and it is distinguished by alluvial organisation of stones into transversal ribs. No significant pools are developed because of the small height of steps that causes low local water scouring. Step-rapid is the most common channel type in BTNR mostly owing to the moderately high gradient of the hill. Out of the 84 channel reaches surveyed, 25 could be assigned to step-rapid morphology. This channel morphology was found in the range of gradients of 3.86-10.34\% in BTNR, with Manning's n ranging from 0.033 to 0.099 and width-to-depth ratios from 4.1 to 45 .

\subsection{Rapid (Plain bed) (Fig. 13C).}

Long reaches of glide, run, or riffle morphology lacking significant pool or bar topography. Moderate-gradient channels dominated by gravel/cobble bed material, with some sand and occasional boulders. Variable confinement and correspondingly variable floodplain extent and hillslope coupling. Low width-to-depth ratios $(\mathrm{w} / \mathrm{h}=12-24)$. Bed surface is typically armoured, with a near-bankfull threshold for significant bed load transport. High sediment supplies reduce the degree of armouring and shift the effective discharge to smaller, more frequent floods. Channel gradients are in the range $1-3 \%$. Of 84 channel reaches surveyed in BTNR, 13 reaches had characteristics similar to those described above - although some of the reaches do not show the typical coarse grain size suggested by Montgomery \& Buffington (1997) - with gradients ranging from 0.83 to $4.77 \%$, width-to-depth ratios of 5.71-27.5, and Manning's n ranging from 0.02 to 0.065 .

\subsection{Pool-riffle (Fig. 13A).}

Alternating pool and bar topography caused by laterally oscillating flow that forces complementary zones of flow convergence (pool scour) and divergence (bar deposition). Spatial variation of flow and bed form deposition promoted by moderate width-to-depth ratios $(\mathrm{w} / \mathrm{h}=15-33)$ and large relative submergence. Typically, moderate- to low-gradient, unconfined channels, with gravel/cobble/sand bed material and extensive floodplains. Decoupled from hillslopes and lateral sediment inputs. Extensive sediment storage in floodplains and bar forms. Susceptible to obstruction-forced pool formation. $S>0.2-1 \%$ (Buffington \& Montgomery, 2013). Twelve channel reaches in Bukit Timah hill are pool-riffle, with gradients of 0.8-3.2\%, width-to-depth ratios of 9.6-52.5, and Manning's n ranging from 0.028 to 0.085 .

\subsection{Forced morphologies (Fig. 13B).}

Flow obstructions can force a reach morphology that differs from the free-formed morphology for an otherwise similar sediment supply and transport capacity. In forested mountain drainage basins, for example, large woody debris may force local scour, flow divergence, and sediment impoundment that respectively form pools, bars, and steps. Forced pool-riffle and step-pool channels are the most common obstruction-controlled morphologies in forested mountain drainage basins. Five force step-pool channel reaches were recognised and most of them were caused by artificial 


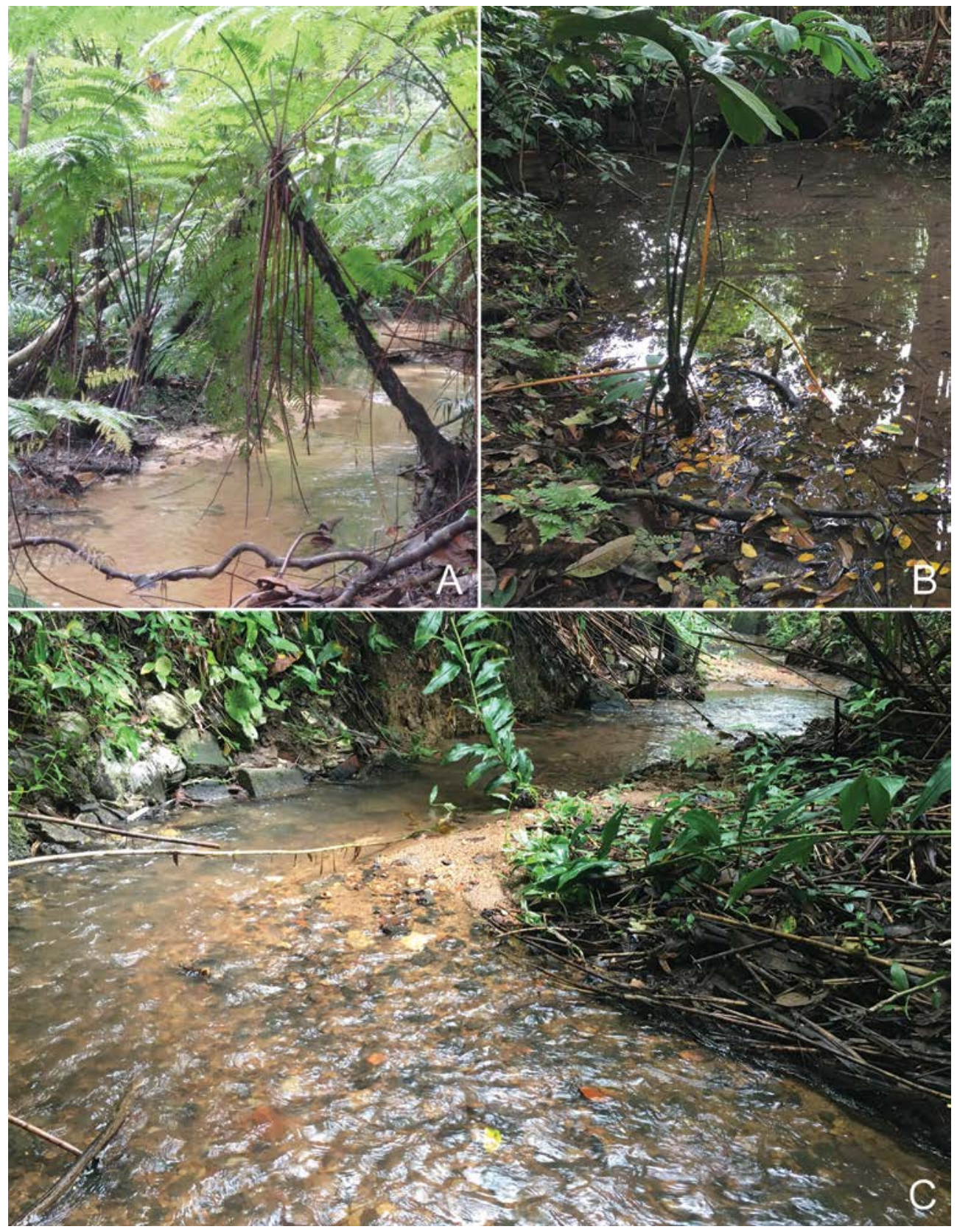

Fig. 13. Channel morphology. A. Pool-riffle, Lasia stream. B. Forced step-pool, Taban stream. C. Rapid, Taban stream. (Photos: Y. Cai) 
structures. These reaches have slope gradients of 2.4-6.7\%, width-to-depth ratios from 6 to 82 , and Manning's n ranging from 0.02 to 0.07 .

For all the streams in BTNR, there is a general downstream progression of reach types that typically proceeds in the sequence colluvial, bedrock, cascade, step-rapid, rapid and pool riffle (Fig. $14 \& 15$ ). This largely agrees with the general distribution of channel types summarised by Montgomery \& Buffington (1997) except that the colluvial and rapid channel types are spread across a wider range of gradients. There is a general trend that low gradient channel forms (poolriffle, rapid, and forced step pool) are with low value of Manning's n, while those with high gradient channel forms (step-pool, cascade and bedrock) are with higher value of Manning's n (Fig. 16).

\subsection{Bed material}

The type of bed material in the stream is a major factor in determining the occurrence of benthic (bottom-dwelling) animals. Pebble counts are only performed to quantify particle size distribution of the surface or armoured layer at selected reaches (Table 8). As the majority of the bedload found in streams of BTNR is sand, visual observation and the sense of touch were used to qualitatively classify and assess the composition. The classification, based on Tolkamp (1980), applied to categories of particles smaller than gravel, were broken down to only two classes, i.e. coarse sand/sand and fine sand/silt. The majority of the bed material is a mixture of sand and coarse sand $(54 \%)$, followed by fine sand/silt (18\%), gravel and cobble $(8 \%)$, pebble $(5 \%)$, boulder and bedrock (4\%) (Fig. 17).

Pebble count was performed for three reaches in Dairy Farm and one reach in Asas stream where significant gravel, pebble and cobble were encountered. At Wallace stream WL1, a reach where coarse sand and gravel are commonly present, a pebble count was also performed for comparison. Results of the $50^{\text {th }}, 84^{\text {th }}$ and $90^{\text {th }}$ percentile of the pebble size for the selected reaches are presented in Table 9. The empirical assumption is that the stream power of a particular stream should be able to move the $\mathrm{d} 84$ or even $\mathrm{d} 90$ of its bedload during a bank-full event. The much greater size of bedload in Dairy Farm and Asas streams may not be a result of natural fluvial formation but is more likely to be linked with the former quarry activity in these two areas.

\subsection{Riparian vegetation}

Values of 1 to 4 were assigned to represent a range from simple to complex vegetation structure. Based on the assessment (Fig. 18), the riparian vegetation of Jungle Fall, Taban, Catchment, Dairy Farm and Rail corridor streams is comparatively well structured, with various layers of plants providing better supporting conditions for the stream habitats.

Canopy cover measures how well a reach of stream channel is shaded under the forest canopy. The canopy cover is important for water temperature as well as being an indication of potential woody debris input to the site. The results (Fig. 19) show that all streams in BTNR have more than 80\% canopy cover, with Jungle Fall, Dairy Farm, Lasia and Seraya streams being the most shaded. Asas and Taban streams have the least cover. 


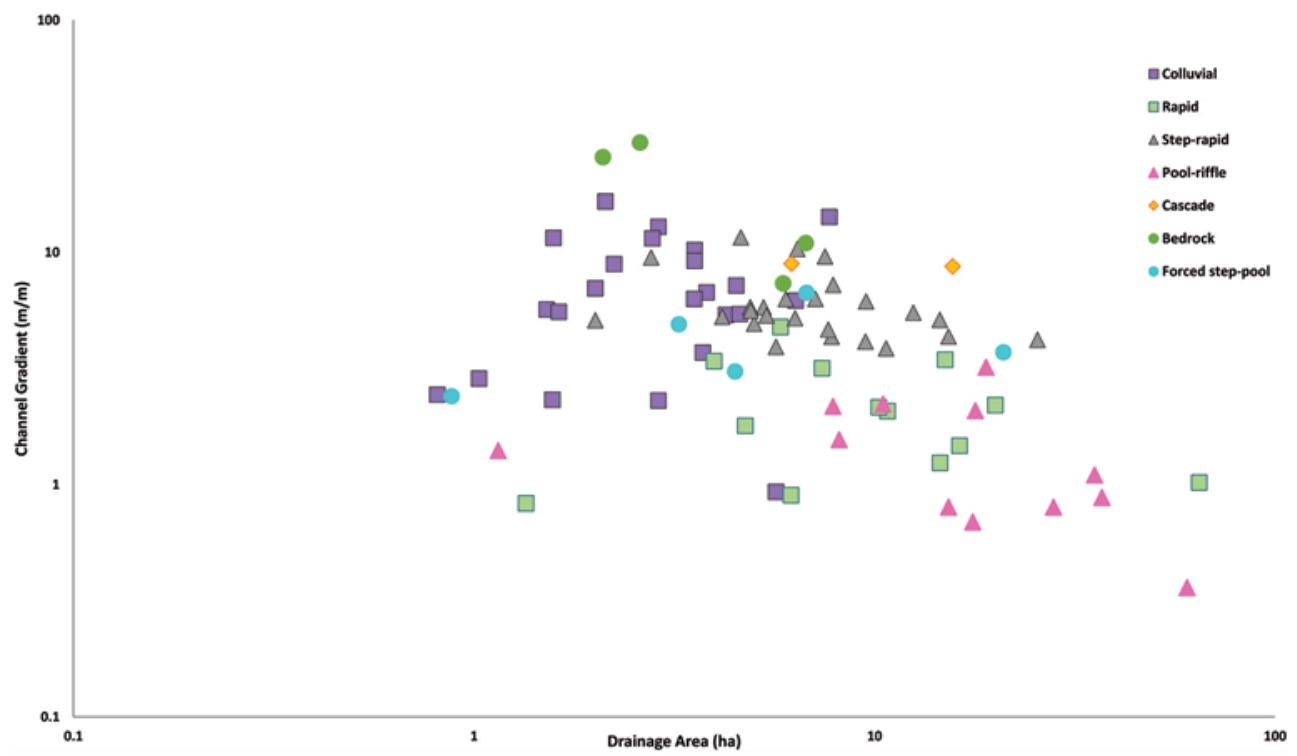

Fig. 14. Plot of contributing area against local gradient for various channel forms in Bukit Timah.

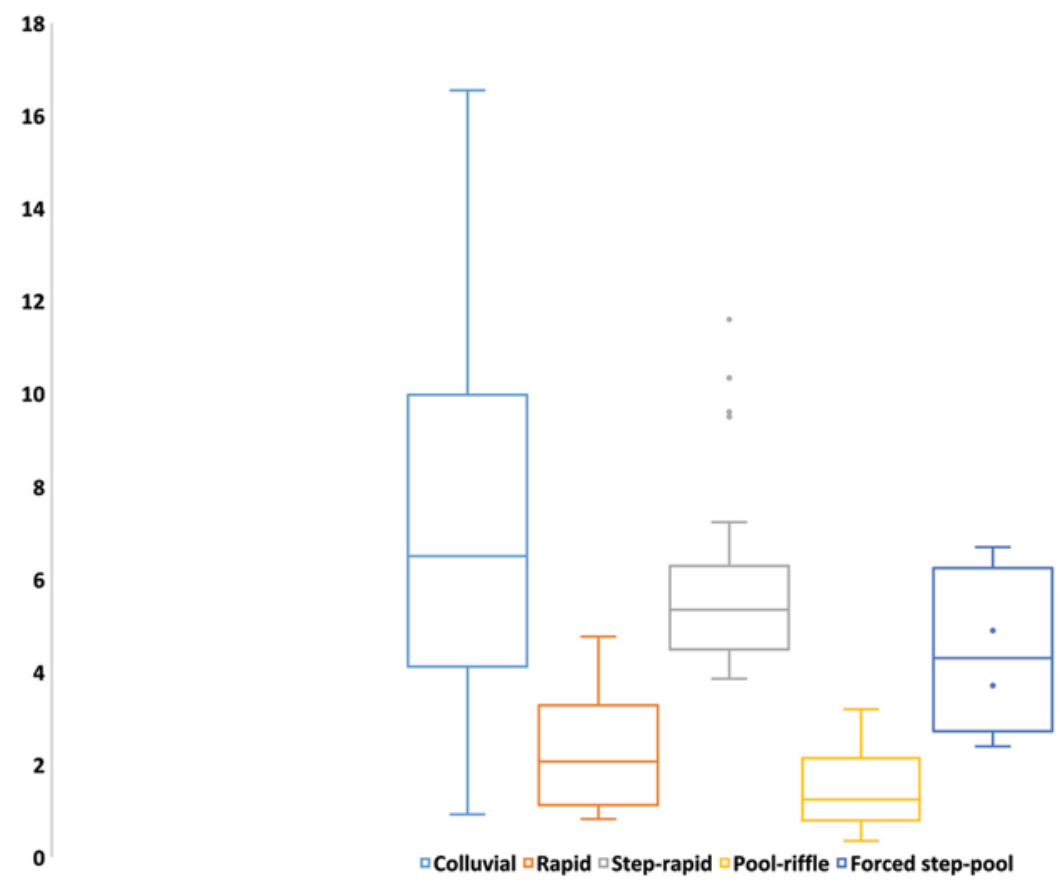

Fig. 15. Quartile chart of selected channel forms and corresponding channel gradient (\%) for streams in Bukit Timah. 


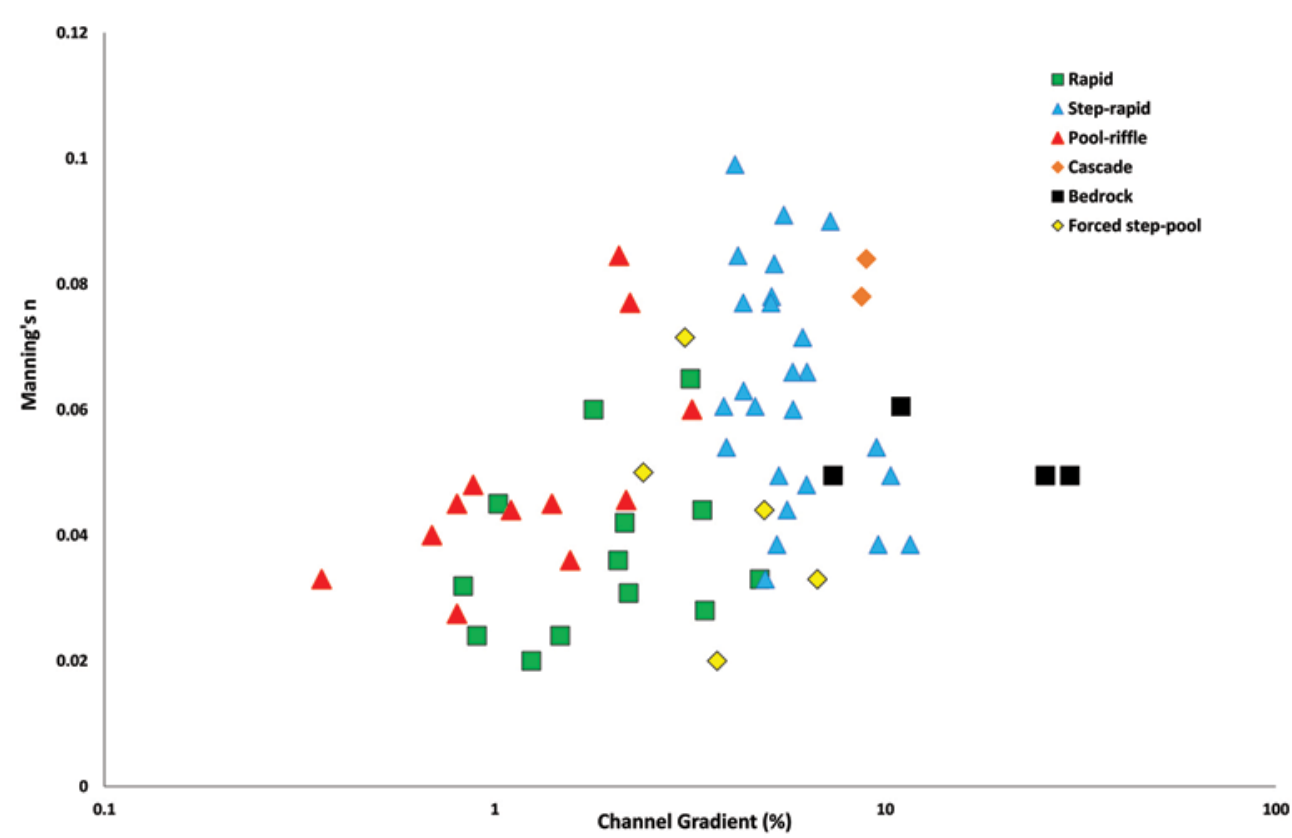

Fig. 16. Manning's friction factor (n) for streams in Bukit Timah.

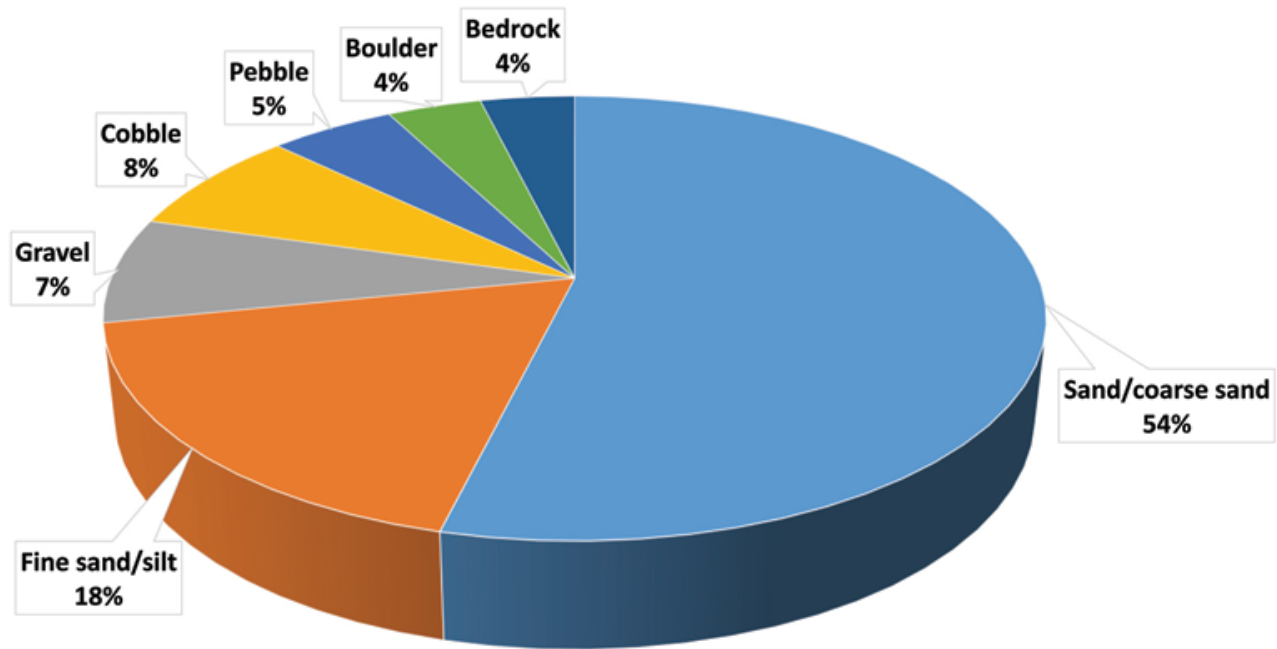

Fig. 17. Composition of bed material of streams in Bukit Timah (\%).

Qualitative observations show that fallen trees locally form barriers across the bigger channels, but they do not usually create any significant forced pools owing to channelisation of the streams as well as occasional maintenance work carried out to remove them. 
Table 8. Wentworth classification of substrate particle size and current velocity necessary to move particles (after Cummins, 1962; Tolkamp, 1980).

\begin{tabular}{lll}
\hline Size Category & Particle Diameter $(\mathbf{m m})$ & $\begin{array}{l}\text { Approximate Current Velocity to } \\
\text { move particle }(\mathbf{m} / \mathbf{s})\end{array}$ \\
\hline $\begin{array}{l}\text { Boulder } \\
\text { Cobble }\end{array}$ & $>256$ & \\
Large & $128-256$ & 3 \\
Small & $64-128$ & 2 \\
Pebble & & \\
Large & $32-64$ & 1.5 \\
Small & $16-32$ & 1 \\
Gravel & \\
Coarse & $8-16$ & 0.75 \\
Medium & $4-8$ & 0.5 \\
Fine & $2-4$ & \\
Sand & & \\
Very coarse & $1-2$ & 0.25 \\
Coarse & $0.500-1$ & \\
Medium & $0.250-0.500$ & \\
Fine & $0.125-0.250$ & \\
Very fine & $0.063-0.125$ & \\
Silt & $0.0039-0.063$ & \\
Clay & $<0.0039$ & \\
\hline & & \\
& & \\
\hline
\end{tabular}

\subsection{Sediment transport}

Occasional undercutting of banks and headwater expansion due to the collapse of channel headcuts or soil pipes seem to be the major erosion events occurring in these channels. Chatterjea (1989a, 1994) monitored a cross-section in the lower reach of Jungle Fall valley and found that there were no perceptible changes between September 1985 and April 1987. However, an artificial pool upstream of the monitored site, due to a low dam built in the 1930s, resulted in a low sediment load that may not be representative of all the streams in the study area. In fact, the pool is no longer discernible due to long term sedimentation and siltation (Fig. 1C). Stream water currently flows down from the lower part of the dam, the majority of the sediment being captured behind the dam. As observed in the current survey, the lower reaches of Fern Vally, Lasia and Wallace streams are experiencing both degradation and aggradation. Degradation is happening through the undercutting of banks and 
Table 9. Pebble count results and projected stream flow dynamic parameters at selected channel reaches.

\begin{tabular}{llllllllll}
\hline Sites & $\begin{array}{l}\mathbf{d 5 0} \\
(\mathbf{m m})\end{array}$ & $\begin{array}{l}\mathbf{d 8 4} \\
(\mathbf{m m})\end{array}$ & $\begin{array}{l}\mathbf{d 9 0} \\
(\mathbf{m m})\end{array}$ & $\begin{array}{l}\mathbf{D}(\mathbf{b f}) \\
(\mathbf{m})\end{array}$ & $\begin{array}{l}\mathbf{W}(\mathbf{b f}) \\
\mathbf{( m )}\end{array}$ & $\mathbf{V ~ m} / \mathbf{s}$ & $\begin{array}{l}\mathbf{Q} \\
\mathbf{m}^{3} / \mathbf{s}\end{array}$ & $\mathbf{\Omega} \mathbf{w} / \mathbf{m}$ & $\begin{array}{l}\mathbf{\omega} \\
\mathbf{w} / \mathbf{m}^{2}\end{array}$ \\
\hline WL1 & $<4.0$ & 4.0 & 15 & 0.6 & 3.5 & 1.14 & 2.40 & 207.07 & 59.16 \\
DF4 & 110 & 178 & 190 & 0.33 & 2.9 & 1.06 & 1.02 & 385.12 & 132.80 \\
DF6 & 110 & 230 & 280 & 0.29 & 2.28 & 1.21 & 0.80 & 483.93 & 212.25 \\
DF8 & 110 & 220 & 280 & 0.42 & 1.65 & 0.76 & 0.53 & 376.35 & 228.09 \\
AS2 & 45 & 86 & 94 & 0.31 & 2.1 & 1.35 & 0.88 & 184.78 & 87.99 \\
\hline
\end{tabular}

downcutting of the channel beds, probably during large storm events, and aggradation is happening thereafter when streams are at baseflow. Stream power at baseflow is general too low to move the bedload further downstream.

Sediment originating in the forest is normally generated from tree-falls and uprooting, landslides, surface creep, stemflow-generated erosion downslope of large trees, rain splash, the collapse of soil pipes, gully head retreat and collapse of channel banks. All of these can be seen in BTNR but the sediment produced is rather low. The sediment is transported mostly by surface wash across the slopes into gullies and small channels. Sediment supply however increases when the forest canopy is disturbed and rain falls onto exposed slopes. Chartterjea (1989a) took samples of sheet wash and rills that developed over disturbed soil associated with a replaced pipeline in BTNR. The highest sediment concentrations in sheet flow and rills were 8679 and $5200 \mathrm{mg} / 1$ respectively. Even then, by the time the storm discharge reached the streams, the concentrations were down to about $200 \mathrm{mg} / \mathrm{l}$. If the forest is disturbed, such sites will be heavily eroded and sediment will travel downslope to end in streams (Chatterjea, 1989a, b; Gupta, 1992). At least two such cases were observed during our survey, one at the upper slope of Fern Valley, where the collapse of a large emergent tree brought down many other trees surrounding it, creating a large open space between the channel head and the stream head (Fig. 20). The other occurred at the upper reach of Taban valley.

Direct sediment input describes the recent condition of lateral sediment connectivity between these systems or between an incised channel and its floodplain. It is quantified in terms of magnitude and intensity of inputs in time and space. This variable includes assumed lateral supply of sediment to a channel segment by both colluvial and fluvial processes, e.g., by shallow landslides, incised gullies, or bank failures under the incision of the stream. During this survey, channel reaches with assumed minimal delivery of sediment by lateral colluvial or fluvial processes during ordinary flow events were evaluated as stage 1 . In contrast, the occurrence of 


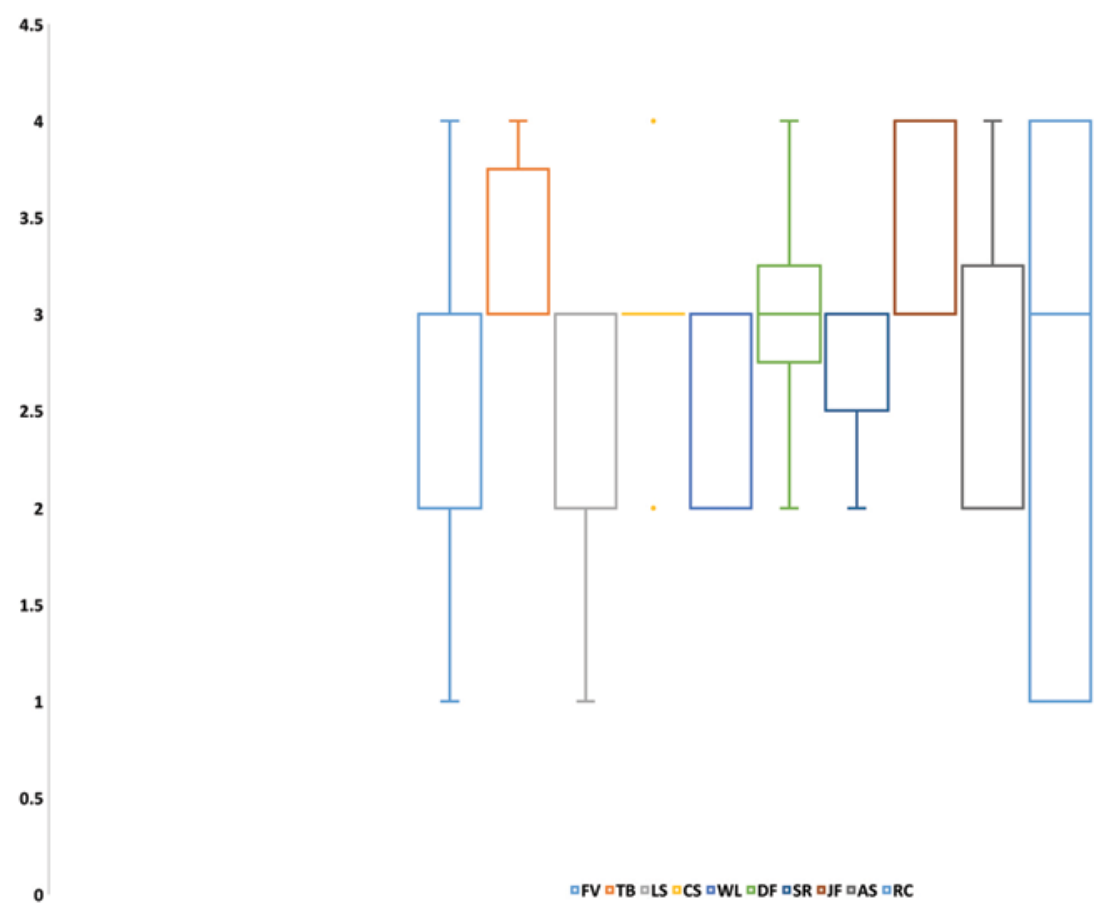

Fig. 18. Vegetation structure of riparian zoon in streams of Bukit Timah.

100

95

90

85

80

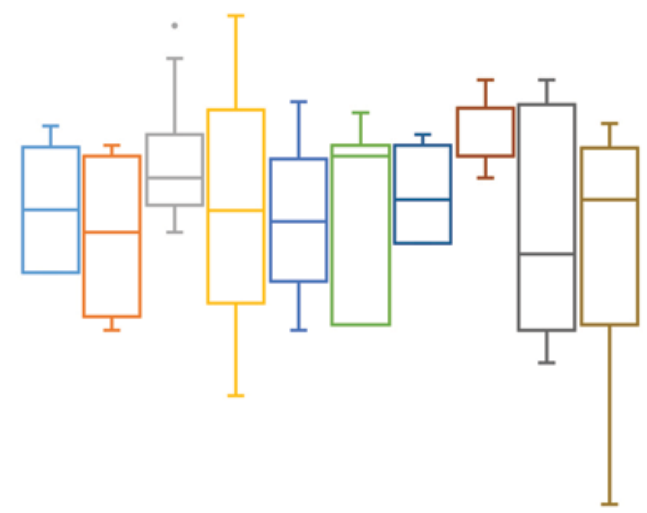

70

65

60

वFV $\square$ TB $\square$ LS $\square$ CS $\square$ WL $\square$ DF $\square$ SR $\square J F \square A S \square R C$

Fig. 19. Canopy cover in the vicinity of various streams of Bukit Timah. 
significant sediment inputs directly affecting channel-reach morphology were evaluated as stage 3 . Stage 2 represented channel reaches with moderate sediment delivery. The longitudinal continuity of sediment transport in the stream channel is not included in this approach (Galia \& Hradecký, 2014b). Assessment of the direct sediment input of streams in Bukut Timah is shown in Fig. 21. Fern Valley, Taban, Lasia and Wallace streams have high direct sediment input. Moderate to intense erosion was observed at the middle reach of Lasia stream (between LS13 and LS16), middle reach of Fern Valley (between FV3 and FV4), middle reach of Dairy Farm (DF9 and DF 15) and lower reaches of Wallace stream (Fig. 22A, between WL8 and WL14), where instability, undercutting and failure of banks have caused earth falls or the fall of overhanging trees, exposing large areas of the riparian tree root mat, resulting in significant bank widening.

The occurrence of channel accumulations is another parameter to assess sediment transport within the stream channel. Channels without accumulations in their cross sections (e.g., without bars or scoured material coming from debris flow events) were recognised as stage 1 . On the other hand, reaches with relatively large amounts of accumulated sediment, often including large wood debris, were recognised as stage 3 ; and the presence of smaller accumulations was recognised as stage 2 (Galia \& Hradecký, 2014b).

The results are presented in Fig. 23. Fern Valley, Taban and Wallace streams all generally experience moderate impact of channel accumulation. Lasia stream shows higher channel accumulation, but only in a few of its lower reaches. Catchment and Asas streams show the least channel sediment accumulation.

The majority of stream channels in BTNR have little sediment and the visible bars are small and low. The point bars are of sand, usually medium to coarse in texture. The streams also tend to carry a suspended load of silty clay which is usually deposited as drapes on bars and as a thin top layer on channel banks and on floodplains if any. These sediment bars are observed mostly at the lower reaches and will frequently be further washed downstream into linear drains beyond the stream outlets. Thus, deposition of sediment at the lower reaches of Fern Valley, Lasia and Wallace streams will not significantly affect the stream function if culverts at the lower reaches of these streams are well maintained. However, several forced step-pools (artificial ponds) near the outlets of other streams, e.g. Catchment, Taban, Seraya and Jungle Fall streams, continuously receive upstream sediment loads and accumulation of sediment with distinct siltation degrading the habitats further.

\section{Conclusions and recommendations}

\section{Hydrogeomorphic baselines for streams of BTNR}

Stream mapping was conducted for BTNR, with detailed information on stream hydrology, hydraulic and geomorphic characteristics being collected to form a baseline dataset for evaluation of various functions that they perform, to analyse the stresses and disturbances that they experience and to recommend follow up actions. 


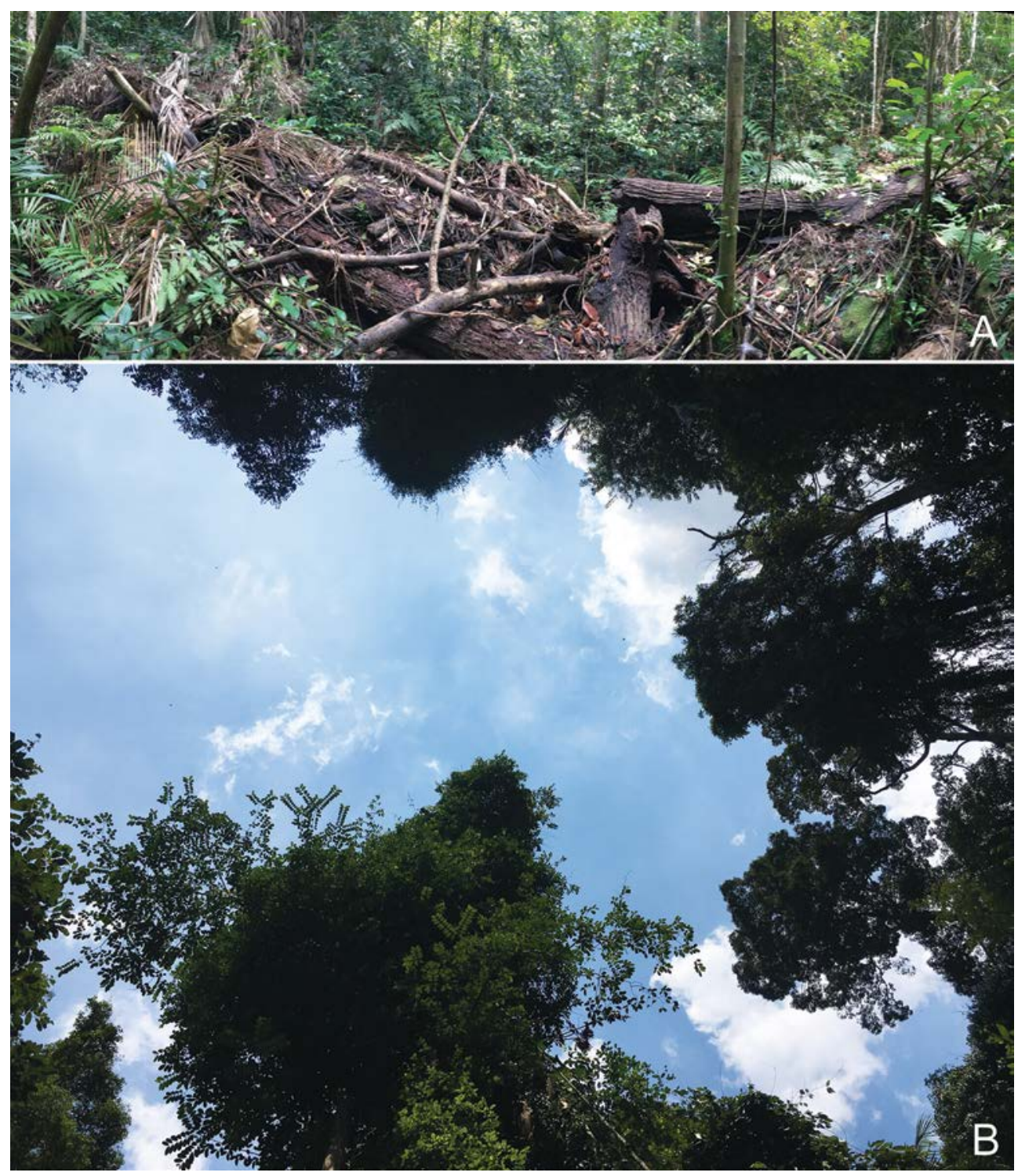

Fig. 20. Impact of an open canopy at Fern Valley stream. A. Fallen trees. B. Canopy break. (Photos: Y. Cai)

\subsection{Hydrology}

Hydrology describes the transport of water from the watershed to the channel, including underground and surface water. Several parameters, e.g. precipitation/ runoff relationship; throughfall, stemflow and evapotranspiration; subsurface stormflow and surface runoff, etc. have been briefly discussed based on a literature review, with additional data from qualitative observations made in the past or during the current stream survey. Located within a well-protected nature reserve, owing to 
2.5

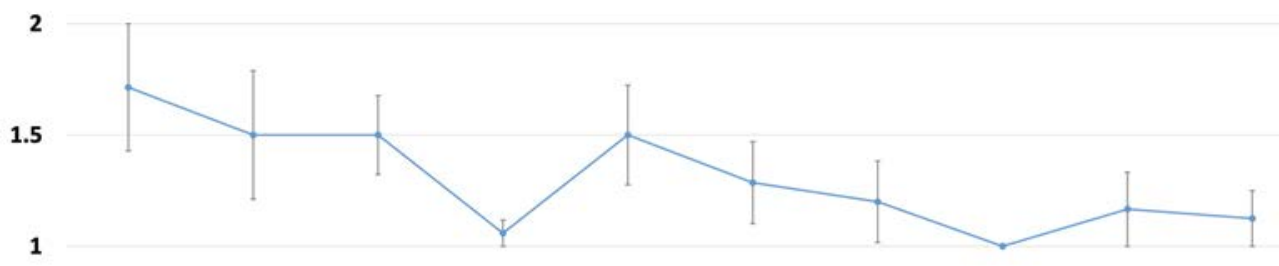

0.5

0

$\begin{array}{llllllllllll}\text { FV } & \text { TB } & \text { LS } & \text { CS } & \text { WL } & \text { DF } & \text { SR } & \text { JF } & \text { AS } & \text { RC }\end{array}$

Fig. 21. Direct sediment input in various streams of Bukit Timah (Error Bar= $\pm 1 \mathrm{SE}$ ).

the nature of high infiltrative soils, in tropical lowland rainforest and with a warm and humid climate, the streams in the study area are expected to continue receiving regular water input to maintain their current baseflow conditions. With the relatively high permeability topsoil of Ferric Acrisol soil, as well as the common occurrence of soil pipes, subsurface flow is believed to be very common and dominates the hydrological processes in BTNR. From the subsurface flow field experiment conducted, a 90:10 split of vertical to lateral tracer flow is reported. Studies in BTNR also suggest that different soil hydraulic properties may exist between two of the small catchments where saturation-excess overland flow was observed during a storm event in one small valley while no overland flow was observed in another, even during a two-year return large storm event. Limited records of discharges seem to indicate that in general, stream flow in BTNR corresponds with the rainfall pattern, with stream discharge normally responding within one or two weeks of lag time.

\subsection{Hydraulics}

Hydraulics focus on the transport of water in the channel, on the floodplain, and through sediments. Quantitative and qualitative data collected from the surveys were analysed based on simple hydrological principles and formulae to give a basic understanding of these topics. The majority of the streams are order 1, with only one order 3 stream, and three order 2 streams, displaying the expected tropical headwater characteristics. The drainage density in the small individual stream catchments varies from 34.2 to $74.2 \mathrm{~m} /$ ha. Though most of the stream lines updated by the current stream mapping exercise are perennial channels, not all channels carry water for any length of time especially in the segments located at the uppermost parts of the channel. Baseflow of the streams is mostly slow, with average flow velocity of $0.127 \pm 0.013 \mathrm{~m} / \mathrm{s}$, ranging from $0.01 \mathrm{~m} / \mathrm{s}$ at one stream head to $0.428 \mathrm{~m} / \mathrm{s}$ at one of the stream outlets during an intermonsoonal 

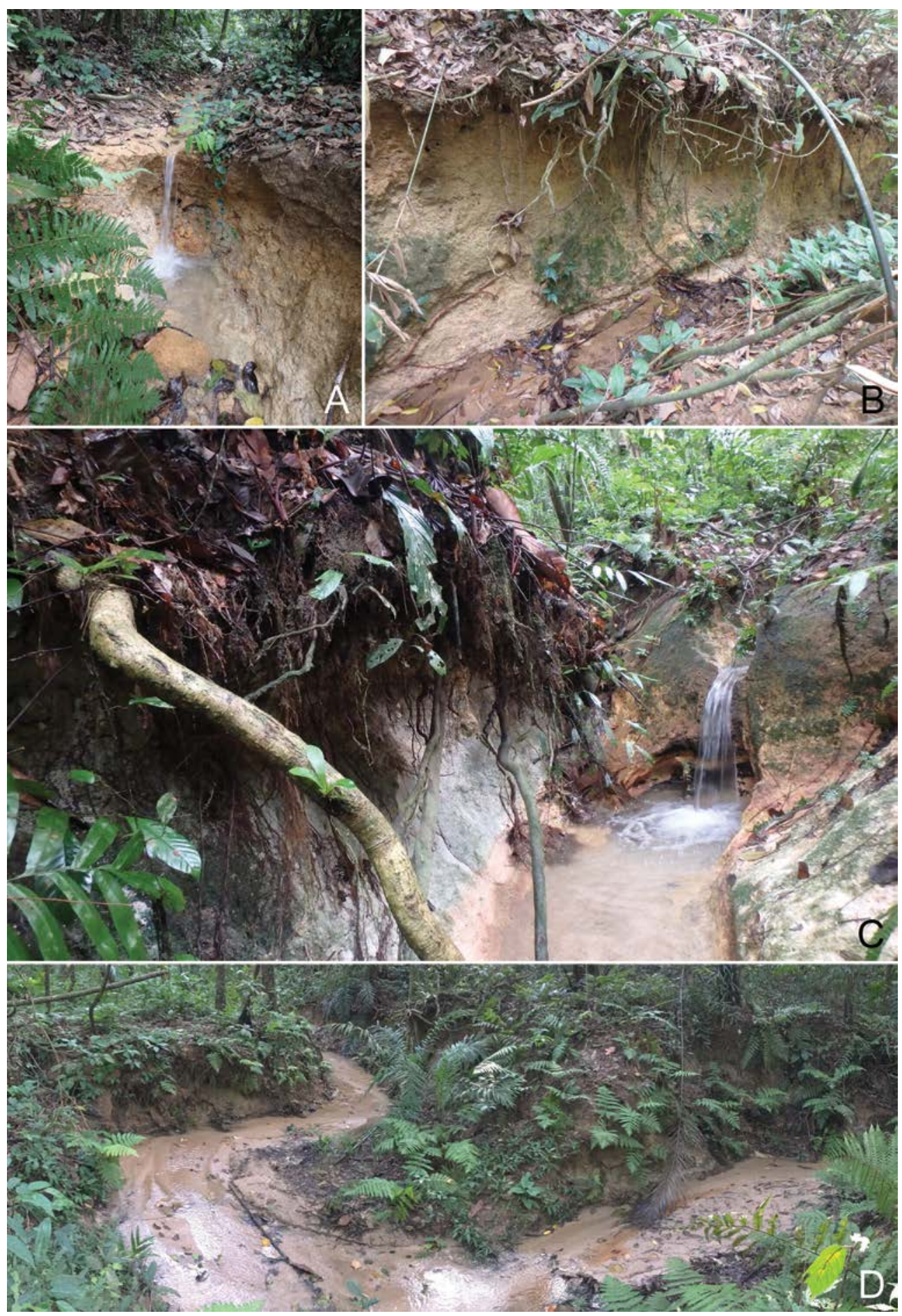

Fig. 22. Showing the degraded channel reaches. A. Wallace stream. B. Dairy Farm stream. C. Lasia stream. D. Fern Valley stream. (Photos: Y. Cai) 
period, and the discharges of various streams are quite variable, from 0.46 to 75.38 $1 / \mathrm{s}$. Mean stream power ranges from 0.029 to $7.54 \mathrm{~W} / \mathrm{m}^{2}$. In bank-full conditions, the flow velocity is projected to rise significantly, from 0.62 to $1.74 \mathrm{~m} / \mathrm{s}$, and mean stream power is projected to be up to more than 100 times in some of the channel reaches. The highly elevated stream power during large storm events may have caused significant channelisation (bank incision, downward bed cutting, and channel headcut) in several reaches at the lower reaches of Fern Valley, Lasia, and Wallace streams, as well as the middle reaches of Dairy Farm and Rail Corridor streams. In BTNR streams, surface and groundwater exchange is quite variable. Most of the streams show a trend of increasing discharge along the channel from the stream head, downslope to the outlet, indicating continuous groundwater input, but a few reaches in the middle sections of some streams show an inverted trend, which suggests a low groundwater table causing the stream to lose water.

\subsection{Geomorphology}

Geomorphology deals with the transport of wood and sediment to create diverse bed forms under dynamic equilibrium. The longitudinal profiles of the streams in Bukit Timah are generally concave upward trends, except for the Jungle Fall and Seraya streams which display slightly convex form. The majority of uphill sections of streams show a high gradient straight line while downhill sections show a lower gradient straight line. The channel head is the most upstream point marking the beginning of fluvial erosion processes on the hillslope and determines the degree of landscape dissection. Twenty channel heads in BTNR hill were mapped with various magnitudes of contributing area (5000-17,200 $\mathrm{m}^{2}$ ), and average gradient of slope above the channel head (S) from 10.25 to $-24.89 \%$. Least squares regression analysis on log-log scale plots yields a negative correlation between A and $\mathrm{S}: A=6.475 S^{-0.145}$ Coefficient of determination shows a weak inverse relationship between contributing area and slope gradient of the channel head, in agreement with results from other tropical areas where, besides overland flow, significant subsurface stormflow plays a major role in channel initiation.

Channel reaches in the streams of BTNR were classified based on Montgomery \& Buffington (1997) who proposed an easy to use process-based classification system relying on visual assessment. The results of such classification can be used to infer the processes and functions each reach performs. Out of the 45 channel reaches surveyed, 24 are colluvial channels, 3 bedrock channels and 57 alluvial channels which include 25 step-rapids, 2 cascades, 13 rapids, 12 pool-riffles and 5 force step-pool channel reaches were recognised. There is a general downstream progression of reach types that proceeds in the sequence colluvial, bedrock, cascade, step-rapid, forced morphology, rapid and pool riffle, which broadly agrees with the general distribution of channel types summarised by Montgomery \& Buffington (1997), except that the colluvial and rapid channel types are spread across a wider range of gradients and with finer bedloads.

The type of bed material in the stream is a major factor in determining the occurrence of benthic (bottom-dwelling) animals. The majority of bed material is a 


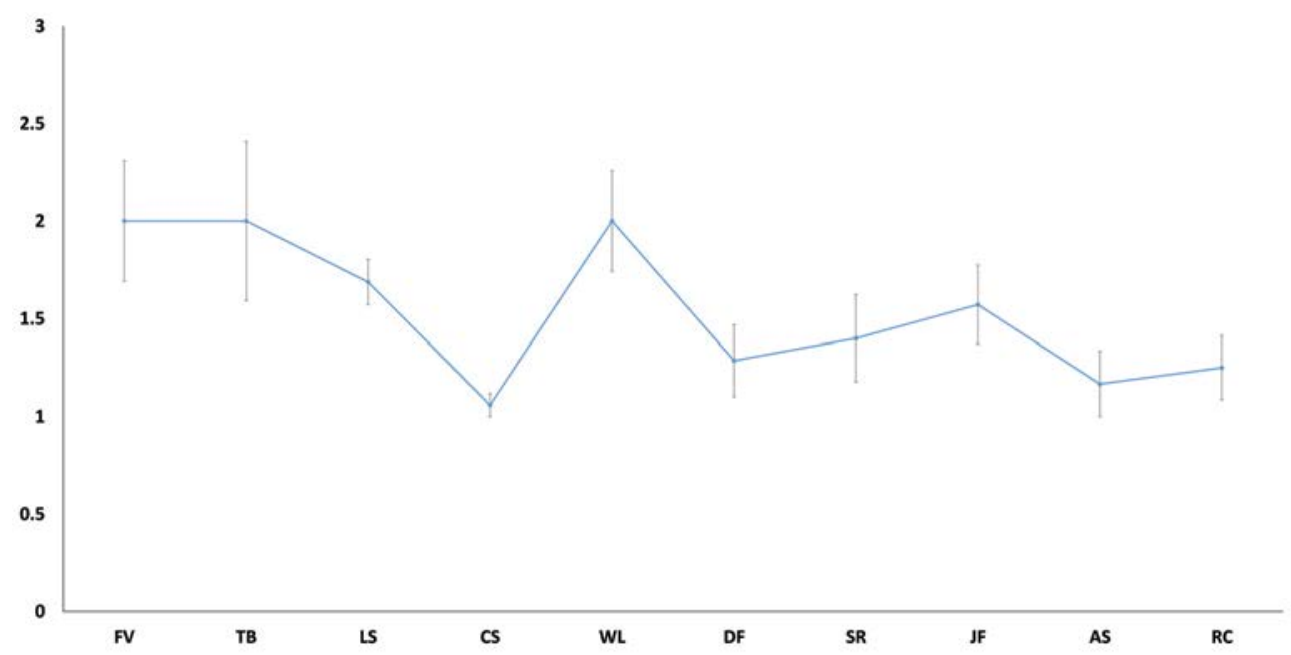

Fig. 23. Occurrence of channel accumulation in various streams of Bukit Timah (Error Bar= $\pm 1 \mathrm{SE})$.

mixture of sand and coarse sand (54\%), followed by fine sand/silt (18\%), gravel and cobble $(8 \%)$, pebble $(5 \%)$, boulder and bedrock $(4 \%)$.

Based on the assessment conducted, the riparian vegetation of Jungle Fall, Taban, Catchment, Dairy Farm and Rail corridor streams is comparatively well structured, with multiple foliage layers from understorey to canopy plants providing support for the stream habitats. The percentage canopy cover results show that all streams have more than $80 \%$ canopy cover, with Jungle Fall, Dairy Farm, Lasia and Seraya streams relatively better shaded than others. Asas and Taban streams are less well shaded.

Sediment in the forest is normally generated from tree-falls, landslides, surface creep, stemflow generated erosion downslope of large trees, rain-splash, the collapse of soil pipes, gully head retreat and collapse of channel banks. All of these were seen to occur in BTNR but the sediment produced is moderately low. Sediment supply however increases when the forest canopy is disturbed and rain falls on exposed slopes, as is likely to have happened in the upper reaches of Fern Valley and Taban valley.

Fern Valley, Taban, Lasia and Wallace streams have high direct sediment input. Moderate to intense erosion was observed at the middle reach of Lasia stream, middle reach of Fern Valley, middle reach of Dairy Farm and lower reaches of Wallace stream, where instability, undercutting and failure of banks have caused past or imminent tree falls and exposed large areas of riparian tree root mat, resulting in significant bank widening.

Overall, most of the channels in BTNR contain little sediment and the bars visible are small and low. The point bars are of sand, usually medium to coarse in texture. The streams also tend to carry a suspended load of silty clay which is usually deposited as drapes on bars and as a thin top layer on channel banks. The sediment bars mostly accumulate downstreamand are further washed into the artificial drains through 
the stream outlets. Deposition of sediment at the lower reaches of Fern Valley, Lasia and Wallace streams will not significantly affect the stream function if culverts are well maintained. However, several forced step-pools (artificial ponds) near the outlets of Catchment, Taban, Seraya and Jungle Fall streams continuously receive upstream sediment loads, and the accumulation of sediment with distinct siltation has degraded the habitats.

\section{Recommendation}

In view of the above assessment, specific recommendations to ensure continued protection of streams in Bukit Timah can be made.

\subsection{Stream rehabilitation}

Implementing hydrological restoration and mitigation measures, e.g., rehabilitation of the channelised lower reaches of Fern Valley, Lasia and Wallace streams for reconnection of floodplain, include reconstruction of instream channel to halt down-cutting, using hydrologically higher resistance bed material; in-fill proper "natural structures" to stabilize channel banks; enhancement of the riparian zone to prevent erosion. These measures can be guided by eco-hydrological models developed from Nee Soon swamp forest, validated with hydrogeomorphic data from the streams in BTNR. Improvement of upstream permeability by good maintenance of public trails; minimising upstream sediment load by revegetation of breaks in the forest canopy, restoration of shallow landslips and headcuts on the upslope. Re-direction of stream flow from current badly degraded incised channels to available alternative dried channels. Such channels could have been functioning before the stream course was diverted by stochastic events.

\subsection{Adaptive management}

Several artificial ponds (classified as "forced step-pools") previously created by road or trail construction have become naturalized, some of them become biodiversity hotspots, e.g. the Catchment pond downstream of Catchment stream (Bastmeijer \& Kiew, 2001; Baker, 2014). Though they have created different and alternative habitats for some of the native aquatic fauna and flora, including species that are critically endangered at national level, these ponds are experiencing hydrological stresses by overloading sedimentation as well as ecological stresses by the introduction of alien species. Management measures such as small scale dragging to remove sediment and silt, as well as active monitoring and removal of the alien species is recommended to enhance the existing habitats. This would have to be done in consultation with the respective biodiversity subject experts. There is a need to encourage, facilitate and integrate research work with adaptive management, and to ensure that the concerns of sustainable stream management are integrated into the nature reserve's operations.

\subsection{Future research}

Encourage in-depth modelling study to better understand the hydrogeomorphic function of streams and the extent of climate change impact in the near future; 
refine eco-hydrological models developed from previous studies. Model-tested data can be applied to guide the restoration designs, and to monitor the resilience of restored streams. To better guide stream management, there is also a need for simple models to be developed that can provide effective predictions from limited site conditions, a need for systematisation and standardisation of observation and measurement.

\subsection{Future monitoring}

Establishing viable sampling protocols for long-term monitoring programmes on restored habitats, and follow-up with adaptive management to ensure the sustainability of the freshwater ecosystems in Bukit Timah. Adoption of standardised survey techniques, such as those applied in the current study, will enable comparison of long-term changes as well as spatial comparisons within the forest catchments and also with locations elsewhere in the context of a national monitoring programme.

ACKNOWLEDGEMENTS. I would like to thank Lena Chan, Geoffrey Davison, Adrian Loo, Lim Liang Jim, Thereis Choo, Cheryl Chia and Liong Shie-Yui for their support, Geoffrey Davison, Liong Shie-Yui, Nguyen Canh Tien Trinh for discussion, Liong Shie-Yui for sharing the groundwater data, Li Tianjiao, Lim Weihao, Daniel Ng, Max Khoo, Melissa Foo, Charmaine Lye, Lim Jing Yang, Cheong Xuan Yong, Claudine Tham, Ong Shu Yi, Audrey Lee, Loh Yu Xuan, Yvonne Nga, Nigel Tiong; Soh Meng Chong; Vivien Wong, Woo Meng Sheng for their assistant with field surveys during the course of the stream study.

\section{References}

Adams, R.K. \& Spotila, J.A. (2005). The form and function of headwater streams based on field and modeling investigations in the Southern Appalachian Mountains. Earth Surf. Process. Landf. 30: 1521-1546.

Bagnold, R.A. (1960). Sediment discharge and stream power: a preliminary announcement, Geological Survey Circular 421. Washington: U.S. Geological Survey.

Bagnold, R.A. (1977). Bed load transport by natural rivers. Water Resour. Res. 13(2): 303-312.

Baker, N. (2014). Black snakeheads at Bukit Timah Nature Reserve. Singapore Biodivers. Rec. 2014: 273.

Bastmeijer, J.D. \& Kiew, R. (2001). A new Cryptocoryne hybrid (Araceae) from the Bukit Timah Nature Reserve, Singapore. Gard. Bull. Singapore 53: 9-17.

Benda, L. (1990). The influence of debris flows on channels and valley floors in the Oregon coast range, USA. Earth Surf. Process. Landf. 15: 457-466.

Bickford, D., Ng, T.H., Qie, L., Kudavidanage, E.P. \& Bradshaw, C.J. (2010). Forest fragment and breeding habitat characteristics explain frog diversity and abundance in Singapore. Biotropica 42: 119-125.

Buffington, J.M. \& Montgomery, D.R. (2013). Geomorphic Classification of Rivers. In: Shroder, J. \& Wohl, E. (eds) Treatise on Geonmorphology, vol. 9, Fluvial Geomorphology, pp. 730-767. San Diego, CA: Academic Press San Diego.

Cai, Y., Nga, Y.P.Q. \& Ngiam, R.W.J. (2019). Diversity and Distribution of Dragonflies in Bukit Timah Nature Reserve, Singapore. Gard. Bull. Singapore 71 (Suppl. 1): 293-316. 
Chan, L. \& Davison, G.W.H. (2019). Introduction to the Comprehensive Biodiversity Survey of Bukit Timah Nature Reserve, Singapore. Gard. Bull. Singapore 71 (Suppl. 1): 3-17.

Chappell, N.A. (2010). Soil pipe distribution and hydrological functioning within the humid tropics: a synthesis. Hydrol. Process. 24: 1567-1581.

Chappell, N.A. \& Sherlock, M.D. (2005). Contrasting flow pathways within tropical forest slopes of Ultisol soils. Earth Surf. Process. Landf. 30: 735-753.

Chatterjea, K. (1989a). Observations on the fluvial and slope process in Singapore and their impact on urban environment. Ph.D thesis, Department of Geography, National University of Singapore.

Chatterjea, K. (1989b). Surface wash: the dominant geomorphic process in the surviving rain forest of Singapore. Singapore J. Trop. Geogr. 10: 95-109.

Chatterjea, K. (1994). Dynamics of Fluvial and Slope Processes in the Changing Geomorphic Environment of Singapore. Earth Surf. Process. Landf. 19: 585-607.

Chatterjea, K. (2007). Assessment and demarcation of trail degradation in a Nature Reserve, using GIS: case of Bukit Timah Nature Reserve. Land Degrad. Dev. 18: 500-518.

Chatterjea, K. (2012). Sustainability of an urban forest: Bukit Timah Nature Reserve, Singapore. In: Diez, J. J. (ed.) Sustainable Forest Management, book 2, pp. 143-160. Rijeka: INTECH.

Chatterjea, K. (2019). Bukit Timah, a forest in transition. Gard. Bull. Singapore 71 (Suppl. 1): 419-440.

Corlett, R.T. (1988). Bukit Timah: the history and significance of a small rain-forest reserve. Environ. Conserv. 15: 37-44.

Corlett, R.T. (1992). The ecological transformation of Singapore, 1819-1990. J. Biogeogr. 411-420.

Corlett, R.T. (1997). The vegetation in the nature reserves of Singapore. Gard. Bull. Singapore 49: 147-159.

Cowan, W.L. (1956). Estimating hydraulic roughness coefficients. Agric. Eng. 37: 473-475.

Cummins, K.W. (1962). An evaluation of some techniques for the collection and analysis of benthic samples with special emphasis on lotic waters. Am. Midl. Nat. 67: 477-504.

Davison, G.W.H. \& Chew, P.T. (2019). Historical review of Bukit Timah Nature Reserve, Singapore. Gard. Bull. Singapore 71 (Suppl. 1): 19-40.

Dietrich, W.E. \& Dunne, T. (1978). Sediment budget for a small catchment in mountainous terrain. Z. Geomorphol. 29 (Suppl.): 191-206.

Dietrich, W.E., Dunne, T., Humphrey, N. \& Reid, L. (1982). Construction of sediment budgets for drainage basins. In: Swanson, F.J., Janda, R.J., Dunne, T. \& Swanston, D.N. (eds) Sediment budgets and routing in forested drainage basins, General Technical Report PNW-141, pp. 2-23. Portland, Oregon: Pacific Northwest Forest and Range Experiment Station, US Department of Agriculture, Forest Service.

Galia, T. \& Hradecký, J. (2014a). Channel-reach morphology controls of headwater streams based in flysch geologic structures: an example from the Outer Western Carpathians, Czech Republic. Geomorphology 216: 1-12.

Galia, T. \& Hradecký, J. (2014b). Morphological patterns of headwater streams based in flysch bedrock: Examples from the Outer Western Carpathians. Catena 119: 174-183.

Gupta, A. (1992). Physiography of the Bukit Timah Nature Reserve and the Central Water Catchment area: a preliminary report. Unpublished report. Reports on the Nature Reserves Survey (Phase I). Singapore: National Parks Board. 
Harman, W., Starr, R., Carter, M., Tweedy, K., Clemmons, M., Suggs, K. \& Miller, C. (2012). A function-based framework for stream assessment and restoration projects. Washington DC: US Environmental Protection Agency, Office of Wetlands, Oceans, and Watersheds.

Hewlett, J.D. \& Hibbert, A.R. (1967). Factors affecting the response of small watersheds to precipitation in humid areas. In: Sopper, W.E. \& Lull, H.W. (eds) International Symposium on Forest Hydrology, Proceedings of a National Science Foundation Advanced Science Seminar, pp. 275-290. New York: Pergamon Press.

Horton, R.E. (1933). The role of infiltration in the hydrological cycle. Trans. Am. Geophys. Union 14: 446-460.

Khoo, M.D.Y., Tiong, N.J.L., Li, T., Lim, W., Ng, D.J.J., Nyanasengeran, M., Yeo, D.C.J. \& Cai, Y. (2019). The freshwater decapod crustaceans of Bukit Timah Nature Reserve, Singapore. Gard. Bull. Singapore 71 (Suppl. 1): 575-581.

Knighton, A.D. (1984). Indices of flow asymmetry in natural streams: definition and performance. J. Hydrol. 73: 1-19.

Knighton, A.D. (1998). Fluvial Forms and Processes. London: Edward Arnold.

Knighton, A.D. (1999). Downstream variation in stream power. Geomorphology 29: 293-306.

Lecce, S. (1997). Nonlinear downstream changes in stream power on Wisconsin's Blue River. Ann. Assoc. Am. Geogr. 87: 471-486.

Lee, K.W. \& Zhou, Y. (2009). Geology of Singapore, $2^{\text {nd }}$ ed. Singapore: Defence Science \& Technology Agency.

Lee, Y.X.A. (2015). Biodiversity assessment of aquatic insects in Bukit Timah Nature Reserve streams. B.Sc. thesis, School of Biological Sciences, Nanyang Technological University.

Leong, T.M., Lee, B.Y.H. \& Chou, L.M. (1996). New record of the tree-frog, Theloderma horridum Boulenger (Amphibia: Anura: Rhacophoridae) from Singapore. Raffles Bull. Zool. 44: 475-478.

Leopold, L.B. \& Maddock, T. (1953). The Hydraulic Geometry of Stream Channels and Some Physiographic Implications. Washington DC: US Government Printing Office.

Leopold, L.B., Wolman, M.G. \& Miller, J.P. (1964). Fluvial Processes in Geomorphology. San Francisco: W.H. Freeman.

Li, T.J., Loh, Y.X., Lim, W.H., Nyanasengeran, M., Low, B.W., Tan, H.H., Yeo, D.C.J. \& Cai, Y. (2019). The fish fauna of Bukit Timah Nature Reserve, Singapore. Gard. Bull. Singapore 71 (Suppl. 1): 557-573.

Lim, W.H., Li, T.J. \& Cai, Y. (2015). A new locality in Singapore for the caecilian, Ichthyophis paucisulcus. Nat. Singapore 8: 73-75.

Lum, S. \& Sharp, I. (eds) (1996). A View from the Summit. The story of Bukit Timah Nature Reserve. Singapore: Nanyang Technological University, National University of Singapore and National Parks Board.

Manokaran, N. (1979). Stemflow, throughfall and rainfall interception in a lowland tropical rain forest in Peninsular Malaysia. Malays. For. 42: 174-200.

Meteorological Service Singapore (2019). Driving Transformation for a Sustainable Future. Annual and Sustainability Report, 2017-2018. Singapore: National Environment Agency.

Montgomery, D.R. \& Buffington, J.M. (1997). Channel-reach morphology in mountain drainage basins. Geol. Soc. Am. Bull. 109: 596-611. 
Montgomery, D.R. \& Dietrich, W.E. (1988). Where do channels begin? Nature 336(6196): 232-234.

Ng, P.K.L. (1994). Freshwater habitats. In: Wee, Y.C. \& Ng, P.K.L. (eds) A first look at biodiversity in Singapore, pp. 23-34. Singapore: National Council on Environment.

Nguyen, C.T.T. \& Cai, Y. (2019). Physicochemical characteristics of streams in Bukit Timah Nature Reserve, Singapore. Gard. Bull. Singapore 71 (Suppl. 1): 491-556.

Oon, S.P.S. (2012). Diatom and geochemical indicators of acidification in a tropical forest stream, Singapore. Master's thesis, Department of Geography, National University of Singapore.

Phillips, J. (1989). Fluvial sediment storage in wetland. Water Resour. Bull. 25: 867-873.

Public Utilities Board (2013). Code of practice for surface water drainage. Singapore: Ministry of Environment \& Water Resources.

Rosgen, D.L. (1994). A classification of natural rivers. Catena 22: 169-199.

Rosgen, D.L. (1996). Applied River Morphology. Pagosa Springs, Colorado: Wildland Hydrology.

Scharff, J.W. (1931). The Singapore Cold Storage Dairy Farm in its relation to antimalaria control measures. Malayan Med. J. 6: 82-87.

Schoof, R. (1980). Environmental impact of channel modification, I. J. Am. Water Resour. Assoc. 16: 697-701.

Sherlock, M.D. (1997). Plot-scale hydrometric and tracer characterisation of soil water flow in two tropical rain forest catchments in Southeast Asia. Unpublished PhD thesis, Lancaster University.

Sherlock, M.D., Chappell, N.A. \& Greer, T. (1995). Tracer and Darcy-based identification of subsurface flow, Bukit Timah forest. Singapore. Singapore J. Trop. Geogr. 16: 197-215.

Sherlock, M.D., Chappell, N.A. \& McDonnell, J.J. (2000). Effects of experimental uncertainty on the calculation of hillslope flow paths. Hydrol. Process. 14: 2457-2471.

Stewart, A.D. (1931). Notes on a visit to the Malay Peninsula. Indian Med. Gaz. Aug. 1931: 457-465.

Sun, Y., Wendia, D., Kim, D.E. \& Liong, S.Y. (2016). Development and application of an integrated hydrological model for Singapore freshwater swamp forest. Procedia Eng. 154: $1002-1009$.

Tolkamp, H.H. (1980). Organism-substrate relationships in lowland streams. Doctoral dissertation. Wageningen: Pudoc, Centre for Agricultural Publishing and Documentation.

Winter, T.C., Harvey, J.W., Franke, O.L. \& Alley, W.M. (1998). Groundwater and surface water - a single resource, US Geological Survey Circular 1139. Washington DC: US Geological Survey.

Wohl, E. (2018). The challenges of channel heads. Earth-Sci. Rev. 185: 649-664.

Wolman, M.G. (1954). A method of sampling coarse bed material. EOS, Trans. Am. Geophys. Union 35: 951-956.

Wolman, M.G. \& Miller, J.P. (1960). Magnitude and frequency of forces in geomorphic processes. J. Geol. 68: 54-74. 